\title{
Olive Pomace Phenolic Compounds Stability and Safety Evaluation: From Raw Material to Future Ophthalmic Applications
}

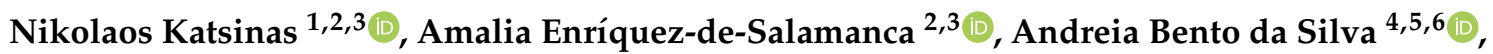 \\ Maria Rosário Bronze ${ }^{4,7,8}$ and Soraya Rodríguez-Rojo ${ }^{1, *(1)}$
}

1 Research Institute on Bioeconomy (BioEcoUVa), High Pressure Processes Group, School of Engineering, University of Valladolid (UVa), Dr. Mergelina Street, 47011 Valladolid, Spain; nkatsinas@ioba.med.uva.es

2 Institute of Applied Ophthalmobiology (IOBA), Campus Miguel Delibes, University of Valladolid (UVa), Paseo de Belén 17, 47011 Valladolid, Spain; amalia@ioba.med.uva.es

3 Biomedical Research Networking Center in Bioengineering, Biomaterials and Nanomedicine (CIBER-BBN), Av. Monforte de Lemos, 3-5, 28029 Madrid, Spain

4 Instituto de Investigação do Medicamento (iMed.ULisboa), Faculdade de Farmácia, Universidade de Lisboa (FFULisboa), Av. Prof. Gama Pinto, 1649-019 Lisbon, Portugal; abentosilva@ff.ulisboa.pt (A.B.d.S.); mrbronze@ff.ulisboa.pt (M.R.B.)

5 Departamento de Ciências Farmacêuticas e do Medicamento (DCFM), Faculdade de Farmácia da Universidade de Lisboa (FFUL), Av. das Forças Armadas, 1649-003 Lisboa, Portugal

check for updates

Citation: Katsinas, N.; Enríquez-de-Salamanca, A.; Bento da Silva, A.; Bronze, M.R.; RodríguezRojo, S. Olive Pomace Phenolic Compounds Stability and Safety Evaluation: From Raw Material to Future Ophthalmic Applications. Molecules 2021, 26, 6002. https:// doi.org/10.3390/molecules26196002

Academic Editors: Ana Barros and Irene Gouvinhas

Received: 12 August 2021

Accepted: 29 September 2021

Published: 2 October 2021

Publisher's Note: MDPI stays neutral with regard to jurisdictional claims in published maps and institutional affiliations.

Copyright: (c) 2021 by the authors. Licensee MDPI, Basel, Switzerland. This article is an open access article distributed under the terms and conditions of the Creative Commons Attribution (CC BY) license (https:/ / creativecommons.org/licenses/by/ $4.0 /)$.
6 Faculdade de Ciências e Tecnologia da Universidade Nova de Lisboa (FCT NOVA), Largo da Torre, 2829-516 Caparica, Portugal

7 Instituto de Biologia Experimental e Tecnológica (iBET), Apartado 12, 2780-901 Oeiras, Portugal

8 Instituto de Tecnologia Química e Biológica da Universidade Nova de Lisboa (ITQB NOVA), Av. da República, 2780-157 Oeiras, Portugal

* Correspondence: soraya.rodriguez@uva.es; Tel.: +34-983-184-077

\begin{abstract}
Nowadays, increasing interest in olive pomace (OP) valorization aims to improve olive's industry sustainability. Interestingly, several studies propose a high-value application for OP extracts containing its main phenolic compounds, hydroxytyrosol and oleuropein, as therapy for ocular surface diseases. In this work, the stability and accessibility of OP total phenolic and flavonoid content, main representative compounds, and antioxidant activity were assessed under different pretreatment conditions. Among them, lyophilization and supercritical $\mathrm{CO}_{2}$ extraction were found to increase significantly most responses measured in the produced extracts. Two selected extracts (CONV and OPT3) were obtained by different techniques (conventional and pressurized liquid extraction); Their aqueous solutions were characterized by HPLC-DAD-MS/MS. Additionally, their safety and stability were evaluated according to EMA requirements towards their approval as ophthalmic products: their genotoxic effect on ocular surface cells and their 6-months storage stability at 4 different temperature/moisture conditions (CPMP/ICH/2736/99), together with pure hydroxytyrosol and oleuropein solutions. The concentration of hydroxytyrosol and oleuropein in pure or extract solutions was tracked, and possible degradation products were putatively identified by HPLC-DAD-MS/MS. Hydroxytyrosol and oleuropein had different stability as standard or extract solutions, with oleuropein also showing different degradation profile. All compounds/extracts were safe for ophthalmic use at the concentrations tested.
\end{abstract}

Keywords: olive pomace; phenolic extracts; oleuropein; hydroxytyrosol; storage stability; genotoxicity assay

\section{Introduction}

The annual cultivation of olive groves reaches a surface of 10.6 million hectares at a global level (data 2019). Within the last decade, olive oil production worldwide has increased by $20 \%$, being approximately 20,069,835 tons per year for the period 2010-2019. According to FAOSTAT, $72 \%$ of the olive oil is produced by the Mediterranean countries of 
Europe [1]. This fact can be explained by the well-known importance of the Mediterranean diet for human health, with olive oil being its principal fat ingredient [2]. The numerous health benefits of olive oil are mostly related to its antioxidant fatty acids and phenolic compounds [3]. Among the latest, hydroxytyrosol (HT) and oleuropein (OL) are the major representatives with several biological activities reported, such as antioxidant, antiinflammatory, antimicrobial, anticancer, antiatherogenic, and cardioprotective [4]. During olive oil and table olive production, huge amounts of by-products are produced, such as the olive pomace (OP), the mill wastewaters, the stones, and the leaves. The OP is the main by-product generated and is a mixture of olive fruits after the recovery of olive oil, together with vegetation waters and stones [5]. Traditionally, the un-treated OP is used to extract the so-called "OP oil", and afterward, it is burnt or discarded into the soil $[2,5,6]$. Its high organic load and phenolic content, along with its phytotoxic properties, make the OP a potential source of soil, water, or air pollution $[2,7,8]$.

Several alternative applications have been studied for the OP in a biorefinery framework, such as biofuel production and agronomic uses, among others [2,5]. Its valorization as a source of valuable bio-active phenolic compounds is an emerging issue, as the OP is rich in phenolic compounds, including HT and OL $[9,10]$. Numerous studies have valorized the $\mathrm{OP}$ for the recovery of these molecules using different extraction techniques, varying from conventional solid-liquid extraction [11] to intensified and environmentally friendly processes such as microwaves and ultrasounds [12-15]. Recently, our group [16] proposed a combination of two sustainable techniques (supercritical carbon dioxide extraction- $\mathrm{SCCO}_{2}$ and pressurized liquid extraction-PLE) for the selective and optimal recovery of these compounds from the OP. Furthermore, in another study [17], we also demonstrated the strong antioxidant and anti-inflammatory activity of two OP extracts, together with the pure HT and OL (alone or in combination) on human corneal and conjunctival epithelial cells. Di Mauro et al. [18] have also proved the same activities on rabbit corneal cells for polyphenolic fractions from olive mill wastewaters with HT as the major component. Several diseases of the ocular surface include oxidative stress and inflammation in their pathophysiology, such as dry eye and ocular allergy [19-21]. The oxidative damage can also stimulate ocular inflammation [20], while it is involved in conjunctivochalasis [22] and keratoconjunctivitis [23]. Therefore, the use of HT- or OL-rich extracts derived from OP, as well as pure OL and HT, could be a potential treatment for oxidative and inflammatory-related diseases of the ocular surface.

For the approval of these compounds and extracts as an ophthalmic product, it is necessary to previously evaluate their stability and safety. Each olive phenolic compound class demonstrates different stability [24]. For example, secoiridoids such as OL are more unstable and thus can be easily hydrolyzed to simple phenols such as HT $[16,25,26]$. It is also true that the richness of the material in the phenolic compounds of interest can vary depending on geographical, climatic, and varietal issues [27,28]. However, it is also affected by other factors that can be controlled, such as drying and storage conditions. The effect of long-term storage (varying from 8 to 18 months) on the stability or oxidation of the virgin olive oil phenolic compounds has been widely studied at several temperatures (from 5 to $\left.50{ }^{\circ} \mathrm{C}\right)[24,29,30]$. More recently, ${ }^{1} \mathrm{H}-\mathrm{NMR}$ metabolomic fingerprinting of the same material after light (500 lux) and temperature $\left(25,30\right.$, and $\left.35^{\circ} \mathrm{C}\right)$ stress has been performed for 12 or 24 months [31]. It was shown that the olive phenolic compounds, especially secoiridoid derivatives, have low thermal and oxidative stability. Hence, changes in phenolic composition occur during long-term storage (reduction of secoiridoids accompanied by an increase of specific simple phenols), together with glyceride degradation and isomerization. For extracts derived from olive leaves, different drying procedures and storage temperatures have been applied either in liquid hydroalcoholic $(80 \% v / v \mathrm{EtOH})$ or solid (dried) form for a short storage period of 4 weeks [32]. A significant reduction of their total phenolic content (TPC) and antioxidant activity (AA) was observed after drying. However, storage did not affect any of the responses measured regardless of the storage temperature or the extract form (liquid or solid). In addition, Di Mauro et al. [18] proved that the HT percentage 
of an ophthalmic hydrogel comprising a polyphenolic fraction derived from olive mill wastewaters can remain stable for 3 months at $25{ }^{\circ} \mathrm{C}$. However, to our knowledge, a study about the stability of the OP phenolic compounds under different conditions has not yet been performed either for the raw material or for aqueous solutions of pure OP compounds or extracts.

The mandatory tests for the approval and release of a pharmaceutical product or drug substance in the market include long-term storage stability and in vitro or in vivo genotoxicity assays. The European Medicines Agency (EMA) guidance CPMP/ICH/2736/99 determines the different thermal and moisture storage conditions in which a pharmaceutical product should remain stable, covering storage, shipment, and subsequent use of the product [33]. Depending on the intended storage condition of the future product, long-term, accelerated, and intermediate storage conditions are described. Usually, long-term storage should cover a minimum of 12 months' duration, while for intermediate or accelerated studies, a period of 6 months is proposed. However, no degradation protocols have been set for OP extract or OL, while no composition standards exist for the OP extract or powder. For HT, its concentration in the olive oil has been studied during long-term degradation, while impurities have been identified generated by its semi-synthesis or fermentation solution $[34,35]$. For this reason, authorization as a "novel food ingredient" has been obtained for this molecule [36]. However, none of the protocols have been established for aqueous HT solutions. Furthermore, in the British, European, and United States Pharmacopoeias, there are monographs only for olive leaf powder and dry extracts, describing the standards with which they should comply in terms of composition (content in OL) and contaminants (microorganisms) [37-39]. Regarding the mandatory tests for genotoxicity, the ICH guideline S2 (R1) by EMA determines the different assays acceptable for screening possible genetic damage, to predict and avoid potential human risks [40]. Among them, the comet assay is proposed as a reliable and common technique to detect the in vitro genotoxicity of a compound, detecting various types of DNA damage in individual cells $[40,41]$. For HT, all genotoxicity studies established so far are based on microorganisms and not human cells, while they all concern its oral use and not its topical ophthalmic application [34].

The objective of this work was to evaluate HT, OL, or OP extracts as a future ophthalmic pharmaceutical product, contributing to the valorization of an agro-industrial by-product potentially hazardous for the environment. The effect of storage conditions of the raw material on the stability of its major phenolic compounds has been studied, together with the long-term stability of aqueous solutions of OL, HT, and two different dried OP extracts at four different temperatures (T) and relative humidity (RH) storage conditions (based on the guidance CPMP/ICH/2736/99). Degradation by-products of olive phenolic compounds have been putatively identified by HPLC-DAD-MS/MS and the degradation profile between the extracts and the pure compounds was compared. Furthermore, the in vitro genotoxicity (comet assay) of the solutions has been evaluated on human corneal and conjunctival epithelial cells, to ensure that the possible future drug substances comply with the safety guidelines.

\section{Results and Discussion}

\subsection{Effect of Pretreatment Conditions on the Material}

To screen the stability of major phenolic compounds in the raw material-OP-different pretreatment conditions were tested: fresh, de-frozen, freeze-dried, and dried. The material was subjected to extraction directly after the pretreatment took place, using the same conventional solid-liquid phenolic procedure. It was evaluated in terms of richness in TPC, total flavonoid content (TFC), OL, oleacein (OLC), HT, and tyrosol (TY), as well as extraction yield (EY) and AA. Table 1 presents the results obtained for each of the tests performed for each condition. Furthermore, analysis of variances (ANOVA) was performed for each response among the different pretreatment conditions, to highlight the statistical significance of the results ( $p$-values presented in Table S1, Supplementary Material). 
Table 1. Results obtained for extracts generated by conventional phenolic extraction conditions, using olive pomace (OP) pretreated at different conditions. Values with different lowercase letters in the same column are significantly different $(p<0.05)$.

\begin{tabular}{|c|c|c|c|c|c|c|c|c|}
\hline Material & $\underset{\left(\mathbf{m m o l}_{\mathrm{TE}} / \mathrm{g}_{\mathrm{DE}}\right)}{\mathbf{A A}}$ & $\begin{array}{c}\text { TPC } \\
\left(\mathrm{mg}_{\mathrm{GAE}} / \mathrm{g}_{\mathrm{DE}}\right)\end{array}$ & $\begin{array}{c}\mathrm{TFC} \\
\left(\mathrm{mg}_{\mathrm{CATE}} / \mathrm{g}_{\mathrm{DE}}\right)\end{array}$ & $\begin{array}{c}\mathrm{OL} \\
\left(\mathrm{mg} / \mathrm{g}_{\mathrm{DE}}\right)\end{array}$ & $\begin{array}{c}\text { OLC } \\
\left(\mathrm{mg}_{\mathrm{OLE}} / \mathrm{g}_{\mathrm{DE}}\right)\end{array}$ & $\begin{array}{c}\mathrm{HT} \\
\left(\mathrm{mg} / \mathrm{g}_{\mathrm{DE}}\right)\end{array}$ & $\begin{array}{c}\mathrm{TY} \\
\left(\mathrm{mg} / \mathrm{g}_{\mathrm{DE}}\right)\end{array}$ & $\begin{array}{c}\mathrm{EY} \\
\left(\mathrm{mg}_{\mathrm{DE}} / \mathrm{g}_{\mathrm{DRY} O P}\right)\end{array}$ \\
\hline Fresh & $3.64 \pm 0.15^{b c}$ & $117 \pm 11^{a}$ & $8.0 \pm 0.7^{b}$ & $6.0 \pm 0.8^{b}$ & $3.7 \pm 0.7^{b}$ & $1.0 \pm 0.3^{b c}$ & $1.5 \pm 0.3^{\mathrm{ab}}$ & $134 \pm 15^{b}$ \\
\hline De-frozen & $3.8 \pm 0.3^{b}$ & $130 \pm 1^{a}$ & $10.9 \pm 0.4^{\mathrm{a}}$ & $10.1 \pm 1.3^{c}$ & $5.2 \pm 0.3^{b}$ & $1.4 \pm 0.5^{\mathrm{ac}}$ & $1.3 \pm 0.2^{b}$ & $116 \pm 4^{\mathrm{ab}}$ \\
\hline Freeze-dried & $4.36 \pm 0.08^{\mathrm{a}}$ & $131 \pm 27^{\mathrm{a}}$ & $11.2 \pm 1.3^{\mathrm{a}}$ & $3.4 \pm 0.5^{\mathrm{a}}$ & $12.0 \pm 3.3^{\mathrm{a}}$ & $1.9 \pm 0.3^{\mathrm{a}}$ & $1.9 \pm 0.2^{a}$ & $94 \pm 6^{a}$ \\
\hline Dried & $3.2 \pm 0.12^{c}$ & $105.0 \pm 0.5^{\mathrm{a}}$ & $5.0 \pm 0.2^{c}$ & $2.53 \pm 0.01^{\mathrm{a}}$ & $2.4 \pm 0.3^{b}$ & $0.17 \pm 0.07^{b}$ & $0.28 \pm 0.01^{c}$ & $112 \pm 6^{a b}$ \\
\hline
\end{tabular}

Results are presented as average \pm standard deviation (SD). Responses measured: antioxidant activity (AA一expressed as mmol of Trolox equivalents (TE)/g dry extract (DE)); total phenolic content (TPC—expressed as mg of gallic acid equivalents (GAE)/g DE; total flavonoid content (TFC - expressed as mg of catechin equivalents (CATE)/g DE), extract richness in oleuropein (OL), oleacein (OLC), hydroxytyrosol (HT), and tyrosol (TY) (expressed as mg of compound/g DE, OLC was calculated as OL equivalents: OLE); and extraction yield (EY-expressed as mg of DE/g dry OP).

According to the results, the pretreatment of the raw material can highly affect the stability of the main compounds. The freeze-dried material demonstrated the highest stability for all measured phenolic compounds, except OL. In fact, freeze-drying has been proved to be a cell disruption method [42,43]. By freezing and subsequent sublimation of water, the cell walls are harmed, increasing the recovery of the compounds of interest [44] and explaining why most of the responses measured are increased by this method. On the other hand, the dried OP demonstrated the lowest stability for all responses measured.

Compared to the fresh OP, the de-frozen had significantly higher TFC (ca. 36\%), while the freeze-dried had $40 \%$ more TFC and $22 \%$ stronger AA. An increase of $8 \%$ for the AA was also observed for the de-frozen. However, it was not considered statistically significant. Between the freeze-dried and de-frozen OP, the AA was significantly higher in the first case. In terms of TPC, the variations observed among the different pretreatment conditions were not considered statistically significant. Regarding the extract richness in the compounds of interest, HT and TY were significantly higher in the freeze-dried material ( $90 \%$ more HT compared to fresh, while $46 \%$ more TY compared to the defrozen). A statistically significant increase of the dry extract (DE) richness in OLC by $224 \%$ compared to the fresh and by $230 \%$ compared to the de-frozen was also observed after lyophilization. However, OL demonstrated a remarkable decrease in the freeze-dried OP (by $66 \%$ compared to the de-frozen and by $43 \%$ compared to the fresh), while it was significantly increased in the de-frozen material compared to the fresh (by 68\%). As it can be observed, the reduction of OL content is accompanied by a proportional increase of OLC richness. This can be explained by possible biotransformation from OL to OLC during the drying process. Sarikaki et al. [45] has already proposed a mechanism for this conversion. This would include cleavage of the methyl ester, followed by a loss of the sugar and an opening of the secologanoside ring, leading to a seco-dialdehyde derivative, which is susceptible to decarboxylation. Regarding the EY obtained, it was also significantly lower after lyophilization (ca. 30\% vs. fresh OP), while there was no remarkable variation among the rest of the pretreatment conditions. For the dried OP, except TPC and EY that did not demonstrate any significant differences, most of the responses measured were much lower. Particularly, TY and TFC showed a significant decrease in comparison to any of the pretreatment conditions tested, while HT and AA were reduced compared to the freeze-dried and the de-frozen OP. Additionally, OLC and OL were significantly lower compared to the freeze-dried or fresh and the de-frozen material, respectively.

Our findings agree with those previously reported in the bibliography. Jiao et al. [46] demonstrated that freeze-thaw pretreatment up to twofold increases the recovery of natural antioxidants, with the highest obtention yields after thawing material storage at $-20{ }^{\circ} \mathrm{C}$. This can be explained by the large ice crystals formed, preventing insoluble components from bounding with the compounds of interest. Additionally, freeze-thaw is a cell disruption method, modifying the cellular structure and increasing the permeability of the cell walls or membranes. Thus, demonstrating higher phenolic availability [47]. According to Zorić et al. [48], drying the raw material can improve its conservation in terms of phenolic compounds, flavonoids, and antioxidant activity. Regarding the drying 
process, Lang et al. [49] proved that an increase in the temperature decreases the TPC and the TFC of the raw material.

Additionally, it is true that with lyophilization the lowest EY was obtained. However, a low EY can benefit the extract richness in the selected compounds, contributing to its final bioactivity. Since our objective was the highest AA and phenolic content, the freeze-dried OP has been selected among the pretreatment conditions tested.

\subsection{Effect of the Defatting Pretreatment Step on the Phenolic Content and Profile of OP Extracts}

The OP is composed of a fraction of residual oil and lipophilic components $[5,6]$ (see Section 3.1. for plant material characterization). The ocular surface consists of mostly water-like tissues, such as tear film and aqueous humor [50,51]. Thus, to achieve good diffusion and of the drug in the ocular tissues, water-based formulations should be designed. Additionally, oil-based drops can cause ocular burning, itching, irritation, and blurry vision $[52,53]$. Therefore, a defatting step prior to the phenolic extract was considered necessary to remove any residual oil from the raw material considering its future application.

For the defatting process, two different methods were performed using freeze-dried $\mathrm{OP}$ : one using $n$-hexane and one using $\mathrm{scCO}_{2}$. As previously described [16], the oil obtained by the two methods, expressed as percentage of the dry basis, was similar. However, in the case of $\mathrm{scCO}_{2}$, toxic organic solvents are avoided, as $\mathrm{CO}_{2}$ is cleaner and non-toxic, being a sustainable and not expensive technique at the industrial level [54]. The effect of these two methods on the stability of the responses (TPC, TFC, OL, OLC, HT, TY, EY, and AA) measured has been screened and compared to the reference material (freeze-dried OP with no further pretreatment). The defatted freeze-dried OP samples were subjected to the same conventional solid-liquid phenolic extraction and the obtained extracts were evaluated as presented in Table 2. The $p$-values of the ANOVA analyses performed for each response comparing the two defatting methods between them and with the reference extract (derived by non-defatted OP) are included in Table S2 (Supplementary Material).

Table 2. Effect of the two defatting pretreatment methods selected on the responses measured for conventional phenolic extracts produced using freeze-dried olive pomace (OP). Values with different lowercase letters in the same column are significantly different $(p<0.05)$.

\begin{tabular}{|c|c|c|c|c|c|c|c|c|}
\hline Material & $\underset{\left(\mathrm{mmol}_{\mathrm{TE}} / \mathrm{g}_{\mathrm{DE}}\right)}{\mathrm{AA}}$ & $\begin{array}{c}\mathrm{TPC} \\
\left(\mathrm{mg}_{\mathrm{GAE}} / \mathrm{g}_{\mathrm{DE}}\right)\end{array}$ & $\begin{array}{c}\mathrm{TFC} \\
\left(\mathrm{mg}_{\mathrm{CATE}} / \mathrm{g}_{\mathrm{DE}}\right)\end{array}$ & $\underset{\left(\mathrm{mg} / \mathrm{g}_{\mathrm{DE}}\right)}{\mathrm{OL}}$ & $\begin{array}{c}\text { OLC } \\
\left(\mathrm{mg}_{\mathrm{OLE}} / \mathrm{g}_{\mathrm{DE}}\right)\end{array}$ & $\underset{\left(\mathrm{mg} / \mathrm{g}_{\mathrm{DE}}\right)}{\mathrm{HT}}$ & $\begin{array}{c}\mathrm{TY} \\
\left(\mathrm{mg} / \mathrm{g}_{\mathrm{DE}}\right)\end{array}$ & $\begin{array}{c}\mathrm{EY} \\
\left(\mathrm{mg}_{\mathrm{DE}} / \mathrm{g}_{\mathrm{DRY} O P}\right)\end{array}$ \\
\hline $\begin{array}{l}\text { Non-defatted } \\
\text { freeze-dried OP } \\
\text { (Reference) }\end{array}$ & $4.36 \pm 0.08^{a}$ & $131 \pm 27^{\mathrm{a}}$ & $11.2 \pm 1.3^{\mathrm{a}}$ & $3.4 \pm 0.5^{\mathrm{a}}$ & $12.0 \pm 3.3^{a}$ & $1.9 \pm 0.3^{\mathrm{a}}$ & $1.9 \pm 0.2^{\mathrm{a}}$ & $94 \pm 6^{a}$ \\
\hline $\begin{array}{c}\text { Freeze-dried OP } \\
\text { defatted with } n \text {-hexane }\end{array}$ & $4.8 \pm 0.5^{\mathrm{a}}$ & $152 \pm 15^{a}$ & $9 \pm 3^{a}$ & $2.6 \pm 0.2^{\mathrm{a}}$ & $12.1 \pm 1.3^{a}$ & $1.9 \pm 0.2^{\mathrm{a}}$ & $1.8 \pm 0.2^{\mathrm{a}}$ & $93 \pm 11^{a}$ \\
\hline $\begin{array}{c}\text { Freeze-dried OP } \\
\text { defatted with } \\
\text { Supercritical } \mathrm{CO}_{2}\end{array}$ & $4.66 \pm 0.14^{\mathrm{a}}$ & $180 \pm 11^{b}$ & $11.2 \pm 1.3^{\mathrm{a}}$ & $3.3 \pm 0.8^{a}$ & $11.8 \pm 1.6^{\mathrm{a}}$ & $1.80 \pm 0.1^{\mathrm{a}}$ & $1.78 \pm 0.10^{a}$ & $121 \pm 25^{a}$ \\
\hline
\end{tabular}

Results are presented as average \pm Standard deviation (SD) and compared with the non-defatted OP. Responses measured: Antioxidant activity (AA-expressed as mmol of Trolox equivalents (TE)/g dry extract (DE)), Total phenolic content (TPC-expressed as mg of gallic acid equivalents (GAE)/g DE, Total flavonoid content (TFC-expressed as mg of catechin equivalents (CATE)/g DE), extract richness in oleuropein (OL), oleacein (OLC), hydroxytyrosol (HT) and tyrosol (TY) (expressed as mg of compound/g DE, OLC was calculated as OL equivalents: OLE), as well as extraction yield (EY-expressed as mg of DE/g dry OP).

According to the results, most of the responses remained stable in both cases. In particular, for the extract derived from $n$-hexane-defatted OP, none of the responses showed any significant variation compared to the reference extract. However, in the case of $\mathrm{scCO}_{2}$, the phenolic extract obtained had significantly higher TPC than the reference one (ca. 37\%). $\mathrm{scCO}_{2}$ displays gas-like transport properties that improve its penetration in the vegetal matrix, while the depressurization step of solvent removal can cause cell disruption [54]. This could explain the higher extraction yield mainly of reducing compounds according to TPC assay, namely phenolic compounds. For the rest of the responses, the variations observed were not considered statistically significant and both defatting processes were similar as well. Thus, it can be said that a defatting step does not affect the phenolic composition of the extract produced afterward. 
Furthermore, the defatting pretreatment allows the recovery of the residual oil of the raw material, the so-called "OP oil", which is already available in the market $[5,6]$. Moreover, the extraction using $\mathrm{scCO}_{2}$ as solvent is a sustainable technique, providing a residual-free extraction product and allowing to obtain an improved quality OP oil compared to the traditional hexane process, as no further refinement is needed [ 54,55$]$.

\subsection{Effect of Extract Drying on Phenolic Retention}

To compare the retention of the phenolic compounds before and after drying, one part of an extract was kept liquid and another one was dried. Regarding the drying process, samples were analyzed in two sequential steps: after ethanol $(\mathrm{EtOH})$ evaporation (step 1-extract still liquid) and after freeze-drying of the extract (step 2-solid extract). Results are presented in Table 3, while the $p$-values of the ANOVA analyses performed for each response are included in Table S3 (Supplementary Material).

Table 3. Effect of extract drying on the retention of the responses measured, compared to a freshly obtained liquid extract (reference: conventional phenolic extract produced using freeze-dried olive pomace (OP)). Step 1 included only ethanol $(\mathrm{EtOH})$ evaporation (extract in liquid state), followed by step 2: freeze-drying of the extract (extract in solid-state). Values with different lowercase letters in the same column are significantly different $(p<0.05)$.

\begin{tabular}{|c|c|c|c|c|c|c|c|c|}
\hline & & $\underset{\left(\mathrm{mmol}_{\mathrm{TE}} / \mathrm{g}_{\mathrm{DE}}\right)}{\mathrm{AA}}$ & $\begin{array}{c}\mathrm{TPC} \\
\left(\mathrm{mg}_{\mathrm{GAE}} / \mathrm{g}_{\mathrm{DE}}\right)\end{array}$ & $\begin{array}{c}\text { TFC } \\
\left(\mathrm{mg}_{\mathrm{CATE}} / \mathrm{g}_{\mathrm{DE}}\right)\end{array}$ & $\begin{array}{c}\mathrm{OL} \\
\left(\mathrm{mg} / \mathrm{g}_{\mathrm{DE}}\right)\end{array}$ & $\begin{array}{c}\text { OLC } \\
\left(\mathrm{mg}_{\mathrm{OLE}} / \mathrm{g}_{\mathrm{DE}}\right)\end{array}$ & $\begin{array}{c}\mathrm{HT} \\
\left(\mathrm{mg} / \mathrm{g}_{\mathrm{DE}}\right)\end{array}$ & $\begin{array}{c}\mathrm{TY} \\
\left(\mathrm{mg} / \mathrm{g}_{\mathrm{DE}}\right)\end{array}$ \\
\hline \multicolumn{2}{|c|}{ Reference: Fresh-Liquid Extract } & $4.36 \pm 0.08^{\mathrm{a}}$ & $131 \pm 27^{a}$ & $11.2 \pm 1.3^{a}$ & $3.4 \pm 0.5^{\mathrm{a}}$ & $12.0 \pm 3.3^{\mathrm{a}}$ & $1.9 \pm 0.3^{a}$ & $1.9 \pm 0.2^{\mathrm{a}}$ \\
\hline \multirow{2}{*}{$\begin{array}{l}\text { Drying } \\
\text { process }\end{array}$} & Step 1 & $4.24 \pm 0.15^{\mathrm{a}}$ & $128 \pm 15^{a}$ & $11.3 \pm 0.9^{\mathrm{a}}$ & $3.2 \pm 0.3^{a}$ & $11.5 \pm 2.4^{\mathrm{a}}$ & $1.65 \pm 0.05^{\mathrm{a}}$ & $1.91 \pm 0.10^{\mathrm{a}}$ \\
\hline & Step 2 & $2.4 \pm 0.2^{b}$ & $70 \pm 10^{b}$ & $10.4 \pm 1.0^{\mathrm{a}}$ & $5.4 \pm 0.8^{b}$ & $7.8 \pm 1.2^{\mathrm{a}}$ & $1.00 \pm 0.12^{b}$ & $1.1 \pm 0.3^{b}$ \\
\hline
\end{tabular}

Results are presented as average \pm Standard deviation (SD). Responses measured: antioxidant activity (AA-expressed as mmol of Trolox equivalents (TE)/g dry extract (DE)); total phenolic content (TPC - expressed as mg of gallic acid equivalents (GAE)/g DE; total flavonoid content (TFC - expressed as mg of catechin equivalents (CATE)/g DE) and extract richness in oleuropein (OL), oleacein (OLC), hydroxytyrosol (HT), and tyrosol (TY) (expressed as mg of compound/g DE, OLC was calculated as OL equivalents: OLE).

It can be observed that the drying process can highly affect the retention of most of the measured responses of the obtained extract. In particular, the AA and the TPC richness of the extract were significantly reduced by $45 \%$ and $47 \%$, respectively; similarly, the HT and the TY richness by $41 \%$ and $42 \%$, respectively. However, the reduction of TFC and OLC was not considered statistically significant, while in the case of OL, a significant increase of $69 \%$ was observed. Hence, depending on the compound, the drying process can selectively affect its retention. It can be said that for labile and more unstable compounds, such as OL and OLC, extract drying can act beneficially. However, for simple phenols (such as HT and TY), the extract drying leads to the loss of almost half of their quantity. The Folin-Ciocalteu method has been considered by many authors as an antioxidant assay and not a quantification method, as it is also based on electron transfer and its results correlate well with the results obtained by AA measurement assays, such as the oxygen radical absorbance capacity (ORAC) [56-58]. In our case, TPC and AA were both decreased similarly, following the bibliography. It is important also to highlight that all changes occur during the step of the sublimation of the water of the freeze-drying, as no statistically significant differences were observed between reference and step 1 . Therefore, the evaporation of EtOH does not affect the retention of any of the responses measured.

\subsection{Evaluation for Ophthalmic Applications of Aqueous Solutions of Selected OP Extracts, OL, and HT}

\subsubsection{Selection of the OP Extracts}

Based on the pretreatment results, the extract produced by conventional solid-liquid extraction from freeze-dried OP (conventional OP extract-CONV) was selected as reference extract. Its selection was also based on its good antioxidant and anti-inflammatory activity on human corneal epithelial (HCE) and immortalized human conjunctival epithelial (IM-ConjEpi) cells [17]. Then, to improve this extract, not only by increasing its richness in phenolic compounds but also by avoiding the presence of oily compounds potentially irritating the ocular surface $[52,53]$, the OPT3 extract was selected. This extract was produced by PLE extraction using freeze-dried OP defatted with $\mathrm{scCO}_{2}$ extraction. 
The operating conditions were optimized in a previous study [16] in comparison to the conventional solid-liquid extraction using the same raw material. Three different optimal extracts were produced by this system, being the OPT3 the optimized extract with the strongest antioxidant and anti-inflammatory activity on HCE and IM-ConjEpi cells [17].

As already mentioned, the inclusion of the defatting step by $\mathrm{scCO}_{2}$ extraction in the production of the extract allows the recovery of two different products: first, the so-called "OP oil" with a cleaner process compared to the conventional extraction with hexane; and second, an aqueous-based phenolic extract at the concentrations required for the ocular application. Thus, the CONV and the OPT3 were selected for further stability and safety evaluation, together with the pure HT and OL, as main phenolic compounds. Before this, a characterization by HPLC-DAD-MS/MS of both extracts was considered necessary, to putatively identify the phenolic compounds present and to compare the phenolic profiles.

\subsubsection{HPLC-DAD-MS/MS Phenolic Characterization of Aqueous Solutions of CONV and OPT3}

The HPLC-DAD-MS/MS analysis was performed for aqueous solutions of $5 \mathrm{mg} / \mathrm{mL}$ of CONV and OPT3 dried extracts. Figure 1 presents the mass chromatogram of CONV (Figure 1A) and OPT3 (Figure 1B). Table 4 includes the phenolic compounds putatively identified for both extracts. Apart from OL, HT, and TY, 12 compounds were putatively identified in CONV solution, and 6 in OPT3 solution.

A.

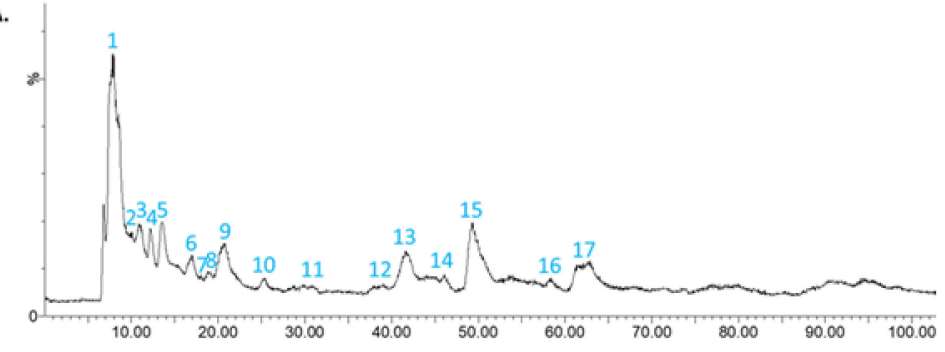

B.

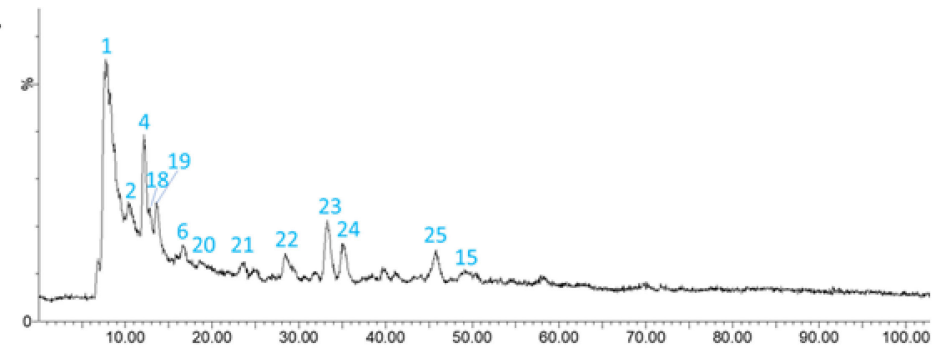

Figure 1. Scan chromatogram in electrospray ionization source in negative mode (ESI - ) for the conventional (CONV) (A) and the optimized (OPT3) (B) olive pomace (OP) dried extracts in aqueous solution.

Table 4. Putative identification of phenolic compounds in the aqueous solution of conventional (CONV) and optimized (OPT3) dried extracts. The table includes the peak numbers as mentioned in the chromatogram (Figure 1A,B), together with the retention time, molecular formula, [M-H]- ion, major electrospray ionization source in negative mode (ESI-) product ions for each compound, and the sample in which they appear.

\begin{tabular}{|c|c|c|c|c|c|c|c|c|}
\hline Peak no & $\begin{array}{c}\text { Putative } \\
\text { Identification }\end{array}$ & $\begin{array}{l}\text { Chemical } \\
\text { Class }\end{array}$ & $\begin{array}{l}\text { Molecular } \\
\text { Formula }\end{array}$ & $\begin{array}{c}\text { Retention } \\
\text { Time (min) }\end{array}$ & $\begin{array}{l}\text { Precursor Ion } \\
\text { [M-H]- }^{-} \\
(\mathrm{m} / \mathrm{z})\end{array}$ & $\begin{array}{l}\text { Product Ion } \\
\quad(m / z)\end{array}$ & References & $\begin{array}{l}\text { Presence in } \\
\text { Sample }\end{array}$ \\
\hline 1 & Quinic acid & $\begin{array}{l}\text { Hydroxybenzoic } \\
\text { acid }\end{array}$ & $\mathrm{C}_{7} \mathrm{H}_{11} \mathrm{O}_{6}$ & 8.22 & 191 & $\begin{array}{c}173,133,127 \\
111,85\end{array}$ & [59] & CONV, OPT3 \\
\hline 2 & Hydroxytyrosol glucoside & Glucoside & $\mathrm{C}_{14} \mathrm{H}_{20} \mathrm{O}_{8}$ & 10.22 & 315 & $153,135,123,89$ & {$[60]$} & CONV, OPT3 \\
\hline 3 & $\begin{array}{l}\text { Unknown } \\
\text { compound } 1\end{array}$ & - & - & 10.84 & 407 & $\begin{array}{c}289,176,151 \\
124,89\end{array}$ & & CONV \\
\hline 4 & Hydroxytyrosol (HT) & Simple phenol & $\mathrm{C}_{8} \mathrm{H}_{10} \mathrm{O}_{3}$ & 12.25 & 153 & 123 & [60] & CONV, OPT3 \\
\hline 18 & $\begin{array}{l}\text { Unknown } \\
\text { compound } 3\end{array}$ & - & - & 12.84 & 143 & $\begin{array}{c}161 \text { (water } \\
\text { adduct of } 143 \text { ) } \\
99,71,45\end{array}$ & & OPT3 \\
\hline
\end{tabular}


Table 4. Cont.

\begin{tabular}{|c|c|c|c|c|c|c|c|c|}
\hline Peak $n^{\circ}$ & $\begin{array}{l}\text { Putative } \\
\text { Identification }\end{array}$ & $\begin{array}{l}\text { Chemical } \\
\text { Class }\end{array}$ & $\begin{array}{l}\text { Molecular } \\
\text { Formula }\end{array}$ & $\begin{array}{l}\text { Retention } \\
\text { Time (min) }\end{array}$ & $\begin{array}{l}\text { Precursor Ion } \\
{\text { [M-H }]^{-}}_{(\mathrm{m} / \mathrm{z})}\end{array}$ & $\begin{array}{l}\text { Product Ion } \\
\quad(\mathrm{m} / \mathrm{z})\end{array}$ & References & $\begin{array}{l}\text { Presence in } \\
\text { Sample }\end{array}$ \\
\hline 5 & $\begin{array}{l}\text { Dialdehydic elenolic acid } \\
\text { decarboxymethyl (DEDA) }\end{array}$ & Secoiridoid & $\mathrm{C}_{9} \mathrm{H}_{12} \mathrm{O}_{4}$ & 13.61 & 183 & $139,95,69$ & [16] & CONV \\
\hline 19 & $\begin{array}{l}\text { Unknown } \\
\text { compound } 4\end{array}$ & - & - & 13.84 & 219 & $111,87,67$ & & OPT3 \\
\hline 6 & Tyrosol (TY) & Simple phenol & $\mathrm{C}_{8} \mathrm{H}_{10} \mathrm{O}_{2}$ & 16.78 & 137 & $\begin{array}{l}134,119,108, \\
84,47\end{array}$ & [59] & CONV, OPT3 \\
\hline 20 & Vanillin & Aldehyde & $\mathrm{C}_{8} \mathrm{H}_{7} \mathrm{O}_{3}$ & 18.76 & 151 & 123,108 & {$[59,61]$} & ОРТ3 \\
\hline 7 & Secologanoside/Oleoside & $\begin{array}{l}\text { Secoiridoid } \\
\text { glycosides }\end{array}$ & $\mathrm{C}_{16} \mathrm{H}_{22} \mathrm{O}_{11}$ & 18.94 & 389 & $\begin{array}{c}165,121,119 \\
89,69\end{array}$ & {$[16,59]$} & $\mathrm{CONV}$ \\
\hline 8 & Elenolic acid glucoside & Secoiridoid & $\mathrm{C}_{17} \mathrm{H}_{23} \mathrm{O}_{11}$ & 19.35 & 403 & $\begin{array}{c}223,179,119,101 \\
89,59\end{array}$ & [59] & CONV \\
\hline 9 & $\begin{array}{l}\text { Unknown } \\
\text { compound } 2\end{array}$ & - & - & 20.61 & 671 & 335,151 & & CONV \\
\hline 21 & 7-epiloganin & Iridoid & $\mathrm{C}_{16} \mathrm{H}_{22} \mathrm{O}_{11}$ & 23.83 & 389 & $151,101,89$ & [59] & OPT3 \\
\hline 10 & $\begin{array}{l}\text { Oleuropein aglycone } \\
\text { derivative }\end{array}$ & Secoiridoid & $\mathrm{C}_{19} \mathrm{H}_{22} \mathrm{O}_{8}$ & 25.27 & 377 & $217,197,153,84$ & {$[16]$} & CONV \\
\hline 22 & $\begin{array}{l}\text { Elenolic acid hexoside } \\
\text { derivative }\end{array}$ & Secoiridoid & $\mathrm{C}_{20} \mathrm{H}_{34} \mathrm{O}_{13}$ & 29.01 & 481 & $371,165,151$ & [61] & OPT3 \\
\hline 11 & Hydroxyoleuropein & Secoiridoid & $\mathrm{C}_{25} \mathrm{H}_{32} \mathrm{O}_{14}$ & 30.60 & 555 & $455,323,223,151$ & [59] & CONV \\
\hline 23 & $\begin{array}{l}\text { Unknown } \\
\text { compound } 5\end{array}$ & - & - & 33.85 & 247 & $139,111,87,41$ & & ОРТ3 \\
\hline 24 & Hydroxytyrosol acetate & Secoiridoid & $\mathrm{C}_{10} \mathrm{H}_{11} \mathrm{O}_{4}$ & 35.63 & 195 & 135,59 & [59] & OPT3 \\
\hline 12 & Verbascoside & $\begin{array}{l}\text { Secoiridoid } \\
\text { glycoside }\end{array}$ & $\mathrm{C}_{29} \mathrm{H}_{36} \mathrm{O}_{15}$ & 37.78 & 623 & 461,161 & [16] & $\mathrm{CONV}$ \\
\hline 13 & Elenolic acid derivative & Secoiridoid & $\mathrm{C}_{11} \mathrm{H}_{14} \mathrm{O}_{6}$ & 41.67 & 241 & $\begin{array}{c}139,127,111,101 \\
95,69\end{array}$ & {$[16]$} & CONV \\
\hline 14 & Nüzhenide & Secoiridoid & $\mathrm{C}_{31} \mathrm{H}_{42} \mathrm{O}_{17}$ & 45.92 & 685 & $\begin{array}{l}523,453,432,421 \\
348,299,223,119\end{array}$ & [16] & $\mathrm{CONV}$ \\
\hline 25 & $\begin{array}{l}\text { Unknown } \\
\text { compound } 6\end{array}$ & - & - & 46.36 & 239 & $150,80,59$ & & OPT3 \\
\hline 15 & Oleacein & Secoiridoid & $\mathrm{C}_{17} \mathrm{H}_{20} \mathrm{O}_{6}$ & 49.32 & 319 & $195,139,95,69$ & [16] & CONV, OPT3 \\
\hline 16 & Oleuropein (OL) & $\begin{array}{l}\text { Secoiridoid } \\
\text { glycoside }\end{array}$ & $\mathrm{C}_{25} \mathrm{H}_{32} \mathrm{O}_{13}$ & 58.20 & 539 & $\begin{array}{c}441,377,341,307 \\
275,223,179,149, \\
119,89\end{array}$ & {$[16,59,61]$} & CONV \\
\hline
\end{tabular}

As it can be observed, the composition of the two extracts is different, although they were obtained from the same raw material. CONV extract contains more complex molecules, such as secoridoids and secoridoid glucosides, while OPT3 comprises mostly smaller compounds, such as simple phenols and iridoids. This can be explained by the different extraction procedures and conditions applied for the obtention of each extract. CONV was extracted at a low $\mathrm{T}\left(70.0^{\circ} \mathrm{C}\right)$ and a medium percentage of ethanol in water $(\% \mathrm{EtOH})(50.0 \%)$, while OPT3 was obtained at high $\mathrm{T}\left(184.0{ }^{\circ} \mathrm{C}\right)$ and $\% \mathrm{EtOH}(90.0 \%)$. The extraction $\mathrm{T}$ can highly affect the type of compounds recovered from the plant material, as thermally labile substances such as secoiridoids can be easily hydrolyzed by applying high $\mathrm{T}$ during the extraction process. For example, it has already been proved that OL can be hydrolyzed to HT at high $\mathrm{T}[16,25,26]$. The $\% \mathrm{EtOH}$ can also affect the compounds obtained in an extract. For example, OL, TY, and HT are better obtained in high \%EtOH, due to solubility reasons $[16,62,63]$. However, the absolute absence of OL in OPT3 can be explained by the high $\mathrm{T}$ applied, leading to its complete decomposition.

\subsubsection{In Vitro Genotoxicity}

According to the ICH guideline S2 (R1), comet assay evaluates the cell DNA damage under a neutral or alkaline electrophoretic field. This leads to the separation between intact and damaged cellular DNA, creating the typical "comet tail" visible from a microscope. By measuring this tail, the extent of the DNA damage can be estimated [41,64]. In this study, we applied alkaline electrophoresis, because it is more sensitive and can detect smaller amounts of DNA damages, including single and double-stranded DNA breaks, alkali labile DNA adducts, and most oxidative DNA damage [65].

Two different human ocular surface cell lines were selected for this assay: HCE and the IM-ConjEpi. The two selected OP extracts (CONV and OPT3) were tested for their in vitro genotoxicity on both cell lines, together with the two principal pure olive compounds OL and $\mathrm{HT}$, alone or in combination (OL+HT). For each compound or extract, the maximum 
allowable concentration was selected to be tested, based on the results of their in vitro cytotoxicity on the same cell lines, as previously described [17]. Hence, the cells were exposed for $24 \mathrm{~h}$ to aqueous solutions of $300 \mu \mathrm{M}$ of OL, $100 \mu \mathrm{M}$ of HT, $5 \mu \mathrm{M}+50 \mu \mathrm{M}$ of $\mathrm{OL}+\mathrm{HT}, 0.4 \mathrm{mg} / \mathrm{mL}$ of OPT3, and $0.8 \mathrm{mg} / \mathrm{mL}$ of CONV.

Figure 2 presents the effect of all compounds and extracts on the DNA of HCE and IMConjEpi cells, expressed as a percentage of DNA present in the comet tail (\%TDNA). From the ROUT analysis, no outliers due to biological diversity or technical errors were detected. From the ANOVA analysis ( $p$-values included in Table S4 of the Supplementary Material), no statistically significant differences between any of the treatment groups and the control group (vehicle: culture medium) were found. Hence, no significant genotoxic effect was produced on HCE and IM-ConjEpi cells, either from CONV and OPT3 or from OL and HT (alone or in mixture) at the selected concentrations. Similarly, Di Mauro et al. [18] found that a purified fraction of olive mill wastewater did not show a genotoxic effect in statens seruminstitut rabbit cornea cells at low concentrations, although DNA damage was induced dose-dependently at higher concentrations.

A

HCE

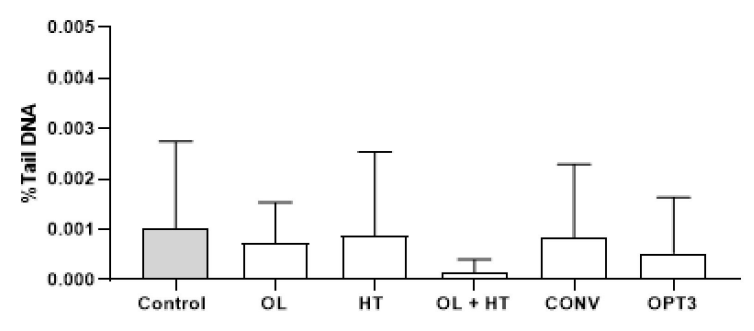

B

IM-ConjEpi

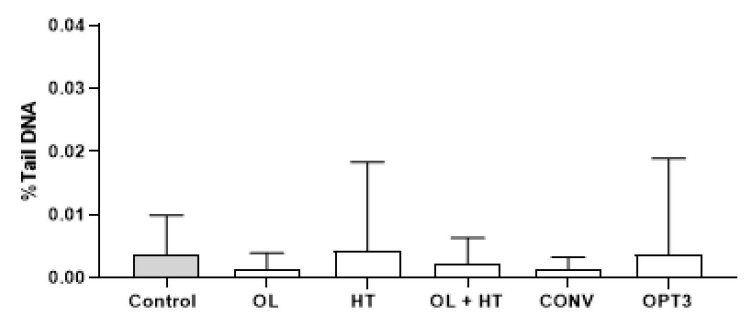

Figure 2. Genotoxic effect (alkaline comet assay) of aqueous solutions of olive pomace (OP) dried extracts $(0.8 \mathrm{mg} / \mathrm{mL}$ conventional-CONV and $0.4 \mathrm{mg} / \mathrm{mL}$ optimized-OPT3), $300 \mu \mathrm{M}$ (162.2 mg/L) oleuropein (OL), $100 \mu \mathrm{M}(15.4 \mathrm{mg} / \mathrm{L})$ hydroxytyrosol (HT) and their mixture $(5 \mu \mathrm{M} / 2.7 \mathrm{mg} / \mathrm{L}+50 \mu \mathrm{M} / 7.7 \mathrm{mg} / \mathrm{L} \mathrm{OL}+\mathrm{HT}$ ) on human corneal (HCE) (A) and conjunctival (IMConjEpi) (B) epithelial cells treated for $24 \mathrm{~h}$. No statistically significant differences have been observed between any of the treatment groups and the control group neither on HCE nor on IM-ConjEpi cells. Results are presented as mean of percentage of DNA present in the comet tail (\%TDNA) \pm standard deviation (SD). Control cells were treated with vehicle (culture medium).

Thus, all OP extracts and compounds tested in this work can be used safely used as topical ophthalmic products.

\subsubsection{Long-Term Storage Stability \\ Effect on \% HT and OL Content}

According to the guidance CPMP/ICH/2736/99, aqueous solutions of HT, OL, OPT3 extract, and CONV extract were stored at four different conditions of temperature (ambient, refrigerated, frozen, and intermediate) and humidity. The conditions were: $\mathrm{T}=5 \pm 3{ }^{\circ} \mathrm{C}$ (with no humidity), $\mathrm{T}=25 \pm 2{ }^{\circ} \mathrm{C}$ (with $60 \pm 5 \% \mathrm{RH}$ ), $\mathrm{T}=30 \pm 2{ }^{\circ} \mathrm{C}$ (with $65 \pm 5 \% \mathrm{RH}$ ) and $\mathrm{T}=40 \pm 2{ }^{\circ} \mathrm{C}$ (with $75 \pm 5 \% \mathrm{RH}$ ) up to a final duration of 6 months. For OPT3, HT was relatively quantified as $\%$ with respect to the concentration $\left(\mathrm{C}_{0}\right)$ at the initial time $\left(\mathrm{t}_{0}\right)$, 
while for CONV both \% HT and \% OL content were calculated similarly. Figure 3 presents the variation during the first 30 days of storage for $\mathrm{HT}$ and $\mathrm{OL}$, either as solutions of pure compounds (Figure 3A for OL and Figure 3B for HT) or as part of the extracts (Figure 3C for OL in CONV, Figure 3D for HT in CONV and Figure 3E for HT in OPT3). The stability of up to 6 months is presented in the Figure S1 of the Supplementary Material.

\section{Standard solutions}

A.

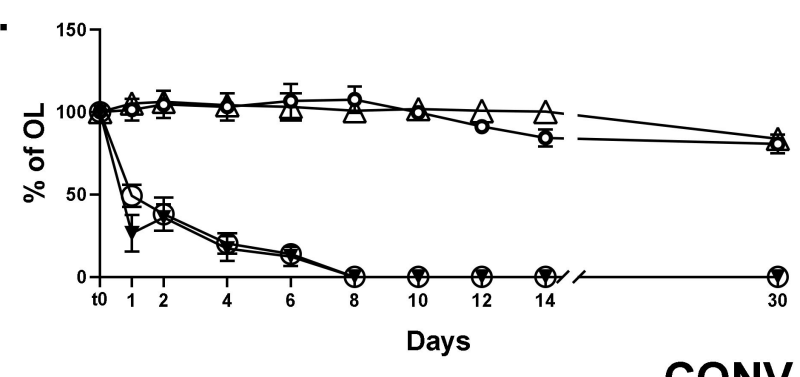

B.

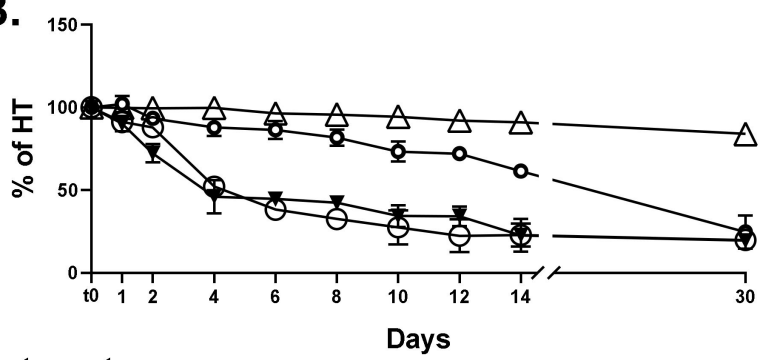

C.

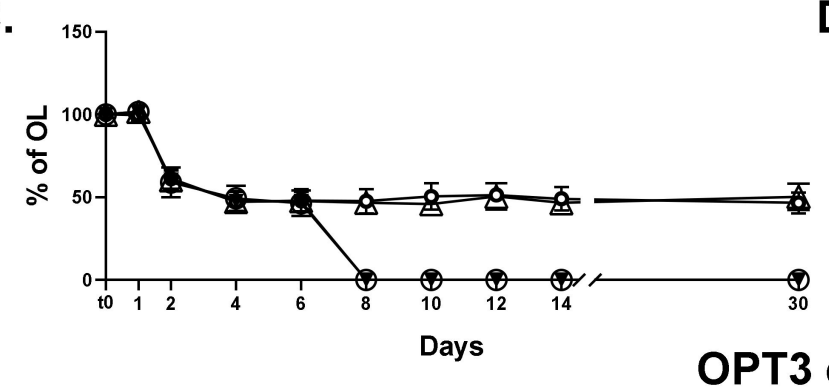

\section{D.}

D.

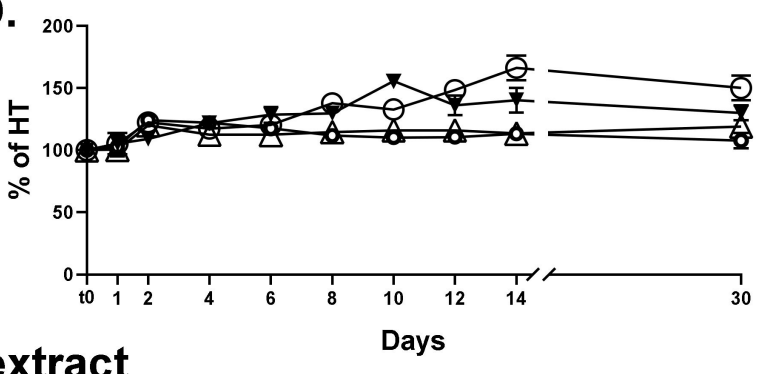

E.

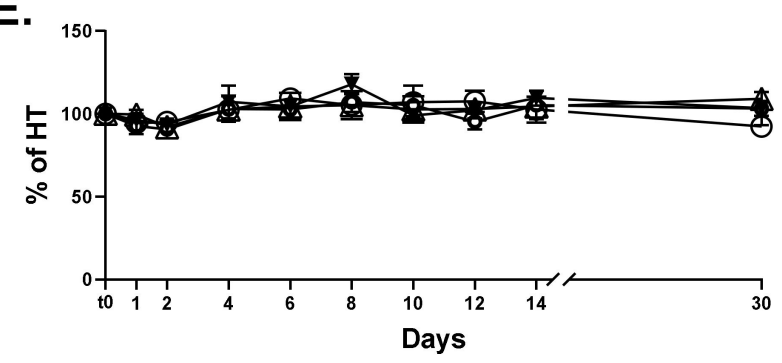

$\mathrm{T}=40 \pm 2{ }^{\circ} \mathrm{C}, 75 \pm 5 \% \mathrm{RH}+\mathrm{T}=30 \pm 2{ }^{\circ} \mathrm{C}, 65 \pm 5 \% \mathrm{RH}-\mathrm{O} \mathrm{T}=25 \pm 2{ }^{\circ} \mathrm{C}, 60 \pm 5 \% \mathrm{RH} \triangle \mathrm{T}=5 \pm 3{ }^{\circ} \mathrm{C}$, no humidity

Figure 3. Stability studies up to 30 days of aqueous solutions of oleuropein (OL) standard (A), hydroxytyrosol (HT) standard (B), OL (C), and HT (D) in conventional (CONV) extract, and HT (E) in optimized (OPT3) extract at four different conditions of temperature $(\mathrm{T})$ and relative humidity $(\mathrm{RH})$. Results are presented as average of percentage of each compound (HT or $\mathrm{OL}$ ) with respect to the initial quantity of $\mathrm{t}_{0} \pm$ standard deviation (SD). Lines are added to guide the eye.

The experimental data of degradation obtained for HT and OL standard solutions during storage at the four different conditions were satisfactorily fitted to pseudo-firstorder kinetics with lag phase $\left(\mathrm{R}^{2}>0.8992\right)$ according to Equation (1) ( $\mathrm{t}$ in days) $[30,66]$. The lag time $\left(t_{\text {lag }}\right)$ represents the time that the concentration of the compound remains constant and, if present, is determined as the intercept of the initial degradation time with the initial concentration value. The half-life period $\left(t_{1 / 2}\right)$ is calculated from Equation (2). The degradation constant $\left(\mathrm{k}_{\mathrm{obs}}\right)$, the $\mathrm{t}_{1 / 2}$, and the time lag $\left(\mathrm{t}_{\mathrm{lag}}\right)$ together with the correlation coefficient $\left(\mathrm{R}^{2}\right)$ for each compound and storage condition are presented in Table 5 .

$$
\begin{gathered}
\ln \left(C_{0} / C_{t}\right)=k_{\text {obs }}\left(t-t_{l a g}\right) \\
t_{1 / 2}=\ln (2) / k+t_{l a g}
\end{gathered}
$$


Table 5. Hydroxytyrosol (HT) and Oleuropein (OL) pure aqueous solutions first-order degradation rate constants ( $\left.\mathrm{k}_{\mathrm{obs}}\right)$, half-time period $\left(t_{1 / 2}\right)$, and lag time $\left(t_{\text {lag }}\right)$ during accelerated stability studies at four different temperature $(T) /$ relative humidity $(\mathrm{RH})$ conditions.

\begin{tabular}{|c|c|c|c|c|c|}
\hline Sample & Storage Conditions & $k_{\text {obs }}\left(\right.$ Days $\left.^{-1}\right)$ & $t_{\text {lag }}$ (Days) & $t_{1 / 2}$ (Days) & $R^{2}(-)$ \\
\hline \multirow{4}{*}{ HT } & $\mathrm{T}=5^{\circ} \mathrm{C} /$ no humidity & 0.0069 & 1.0 & 101.5 & 0.9796 \\
\hline & $\mathrm{T}=25^{\circ} \mathrm{C} / 60 \% \mathrm{RH}$ & 0.0337 & 1.0 & 21.6 & 0.9846 \\
\hline & $\mathrm{T}=30^{\circ} \mathrm{C} / 65 \% \mathrm{RH}$ & 0.1068 & 0 & 6.5 & 0.9691 \\
\hline & $\mathrm{T}=40^{\circ} \mathrm{C} / 75 \% \mathrm{RH}$ & 0.1234 & 0 & 5.6 & 0.9800 \\
\hline \multirow{4}{*}{ OL } & $\mathrm{T}=5^{\circ} \mathrm{C} /$ no humidity & 0.0099 & 11.3 & 81.3 & 0.9833 \\
\hline & $\mathrm{T}=25^{\circ} \mathrm{C} / 60 \% \mathrm{RH}$ & 0.0065 & 9.9 & 116.5 & 0.9732 \\
\hline & $\mathrm{T}=30^{\circ} \mathrm{C} / 65 \% \mathrm{RH}$ & 0.4022 & 0 & 1.7 & 0.8992 \\
\hline & $\mathrm{T}=40^{\circ} \mathrm{C} / 75 \% \mathrm{RH}$ & 0.3658 & 0 & 1.9 & 0.9694 \\
\hline
\end{tabular}

As a pure solution, $\mathrm{OL}$ is highly unstable at temperature values above $30^{\circ} \mathrm{C}$ (Figure $3 \mathrm{~A}$ ), while remains at high levels at $5{ }^{\circ} \mathrm{C}$ or $25^{\circ} \mathrm{C}$ (Figure 3A). From the kinetics results (Table 5), there is no $\mathrm{t}_{\text {lag }}$ for $\mathrm{OL}$ at a temperature above $30^{\circ} \mathrm{C}$, while the time to reduce the concentration to half of the initial value $\left(t_{1 / 2}\right)$ is around 3 days. However, for temperature values below $25^{\circ} \mathrm{C}$, OL remains stable up to approximately 11 days, having a high $\mathrm{t}_{1 / 2}$ in both 5 and $25^{\circ} \mathrm{C}$. HT as a standard solution starts to degrade almost from the first day but at a slower rate in comparison to OL (Figure 3B). Particularly, at $5{ }^{\circ} \mathrm{C}, \mathrm{HT}$ is stable at a high percentage for the entire month. The degradation constant $\mathrm{k}_{\mathrm{obs}}$ increased proportionally with temperature following an Arrhenius type equation (data not shown) for HT standard solution, as well as for OL, although in this case, the variation in concentration at 30 and $40{ }^{\circ} \mathrm{C}$ was nearly the same. Similarly, the $t_{1 / 2}$ decreases proportionally from 101.5 days to 5.6 days as temperature increases for HT.

Nevertheless, HT and OL in the extracts demonstrate different degradation kinetics. This can be explained by the presence of more compounds of the same groups in the extract, which can be transformed/degraded to other molecules, such as HT [30,66]. For $\mathrm{OL}$, the effect of the temperature above $30^{\circ} \mathrm{C}$ is similar as part of the extract or pure solution (Figure 3C). However, regarding the temperatures of $5{ }^{\circ} \mathrm{C}$ and $25^{\circ} \mathrm{C}$, it can be observed that the stability of OL in CONV is different compared to the standard solution, with half of the initial quantity being degraded after $48 \mathrm{~h}$ (Figure 3C). On the other hand, HT concentration in the extracts remains stable or even increases. In particular, as part of OPT3 (Figure 3E), no degradation is observed during the first month, while it can be said that a slight increase occurs. For HT measured in CONV (Figure 3D), a significant increase in its content can be observed from day 2 which is even higher for temperatures above $30{ }^{\circ} \mathrm{C}$. This could be explained by comparing the Figure $3 \mathrm{C}, \mathrm{D}$ and taking into account the conversion of OL into HT $[16,25,26]$. After day 2, a decrease of the OL extract percentage is observed at all conditions, while for temperatures above $30^{\circ} \mathrm{C}$ at day $8, \mathrm{OL}$ is not detected. At the same time points, HT is increased at all conditions (day 2) and especially for high temperatures (day $8-\mathrm{T}=30^{\circ} \mathrm{C}$ and $40^{\circ} \mathrm{C}$ ). These results support this hypothesis. For the OPT3, the presence of OLC in low quantities, a molecule that includes the "HT" moiety in its structure could also support the same premise. In the olive oil, Lozano-Sánchez et al. [66] has already proved the positive correlation between the increase of HT and the decrease of decarboxymethyl oleuropein aglycone, a molecule structurally similar to OLC. The low thermal stability of OL and HT has already been demonstrated $[67,68]$. However, it is important to highlight that the stability of these compounds in aqueous solutions is lower than in solid state [69] or in olive oil [30,66].

Regarding the stability of the compounds and extracts after the first month (Figure S1, Supplementary Material), OL standard solution (Figure S1A) at $5{ }^{\circ} \mathrm{C}$ and $25^{\circ} \mathrm{C}$ is degraded proportionally with the time, reaching a final content of ca. $35 \%$ compared to the $\mathrm{t}_{0}$. In CONV (Figure S1C), OL is completely degraded at $25^{\circ} \mathrm{C}$ from the second month and at $5{ }^{\circ} \mathrm{C}$ from the fifth month. HT as a standard solution (Figure S1B) at $30{ }^{\circ} \mathrm{C}$ and $40{ }^{\circ} \mathrm{C}$ is completely degraded from the third month and at $25^{\circ} \mathrm{C}$ from the fourth month. However, 
at $5{ }^{\circ} \mathrm{C}$, after 6 months, it remains at a concentration of approximately $60 \%$ compared to the initial. The increase of HT concentration in both extracts can be observed even more significantly after the first month, especially for CONV (Figure S1D). In fact, for temperatures above $30^{\circ} \mathrm{C}$, HT reaches a concentration of three to four times higher than that at $\mathrm{t}_{0}$. At temperatures below $25^{\circ} \mathrm{C}$, half of the initial quantity is degraded. Regarding OPT3 (Figure S1E), the tendency is similar to that of CONV extract. At temperatures above $30{ }^{\circ} \mathrm{C}$, the final quantity of $\mathrm{HT}$ is $1.5-1.6$ times higher, while at $25^{\circ} \mathrm{C}$ or $5^{\circ} \mathrm{C}$, it remains at the same levels as at the end of the first month (ca. 110\%). These long-term data support even stronger our hypotheses of molecules transformation within the extracts and their different stability kinetics as pure solutions or extracts.

From the results, it became mandatory to evaluate the chemical degradation profile of all solutions by HPLC-DAD-MS/MS.

\section{HPLC-DAD-MS/MS Profile Comparison}

To investigate the different stability profiles of $\mathrm{HT}$ and OL alone or as part of an extract, an HPLC-DAD-MS/MS analysis was performed for the pure HT, pure OL, CONV, and OPT3 after a 30, 6, 4 and 6 days exposure, respectively, at $40^{\circ} \mathrm{C}$. For CONV and OPT3, a total HPLC-DAD-MS/MS characterization using an electrospray ionization source in negative mode (ESI-) of the $40^{\circ} \mathrm{C}$ exposed extracts was performed, putatively identifying all compounds present in them and comparing the phenolic profiles with those of the initial extracts (freshly prepared) (Table 4).

OL as a pure solution is degraded to two major compounds with $\mathrm{m} / \mathrm{z} 137$ and 403 (Figure S2, Supplementary Material) with 223 and 179 being the major fragments of $\mathrm{m} / \mathrm{z}$ 403 confirming the existence of elenolic acid glucoside (compound 8-Table 4) [59]. This molecule is indeed part of the OL structure. On the other hand, the $\mathrm{m} / \mathrm{z} 137$ corresponds to the "4-ethylbenzene-1,2-diol" part of the OL molecule, left after the removal of the "elenolic acid glucoside" moiety. Thus, it can be said that the bond connecting the ester with the ethyl part is more susceptible to break when OL is a pure solution. However, when OL is part of the extract, its degradation profile seems different. In particular, the $m / z 403$ is also detected in the freshly prepared CONV extract (Table 4). Thus, elenolic acid glucoside can be a secondary metabolite present in the $\mathrm{OP}$ or be produced during the extraction by degradation/transformation of the molecules due to high temperature. In this case, it is not produced during the long-term storage of the extract solution. Additionally, an $\mathrm{m} / \mathrm{z}$ 387 is detected in the extracts. This, together with the increase of HT $(\mathrm{m} / z$ 153) over time (Figure S1D) can confirm that OL, in this case, is degraded by breaking the bond inside the ester and producing the HT and Secologanin moieties.

Regarding HT aqueous pure solution, comparing the UV chromatogram at $280 \mathrm{~nm}$ with the ESI- scan chromatogram of the sample after 30 days exposure at $40{ }^{\circ} \mathrm{C}$, the major mass detected had an $\mathrm{m} / \mathrm{z}$ of 319 at $10.14 \mathrm{~min}$ (Figure S3, Supplementary Material). The same $\mathrm{m} / \mathrm{z}$ was also detected at $13.28 \mathrm{~min}$. Unfortunately, it was not possible to identify the compound corresponding to this mass, since all compounds existing in the bibliography with this $\mathrm{m} / \mathrm{z}$ are not HT by-products. In addition, several peaks were detected in the sample: an $\mathrm{m} / \mathrm{z} 303$ at $26.38 \mathrm{~min}$, an $\mathrm{m} / \mathrm{z} 199$ at $9.54 \mathrm{~min}$, an $\mathrm{m} / \mathrm{z} 151$ at $8.73 \mathrm{~min}$, an $\mathrm{m} / \mathrm{z} 179$ at $15.98 \mathrm{~min}$, and an $\mathrm{m} / \mathrm{z} 113$ at $8.73 \mathrm{~min}$, whose identification was not possible based on the existing bibliography. Further analyses with different identification techniques could help the identification of these degradation by-products in the future.

Attya et al. [67] used tandem mass spectrometry to evaluate the thermal stability of selected phenolic compounds of virgin olive oil. Regarding OL, a fragment with $\mathrm{m} / \mathrm{z} 137$ was formed during its thermal degradation, confirming our hypothesis, and demonstrating that in different materials/conditions, the degradation profile of the molecules may differ. However, in terms of HT, no specific fragments have been presented, due to a possible lack of clear spectrographic results. Some authors have proposed that HT is autoxidized to o-quinone or p-quinone methides that could form dimers possibly not detectable by HPLC-MS/MS after the addition of water [70,71]. 


\section{Materials and Methods}

\subsection{Plant Material and Pretreatment Conditions}

OP obtained from the processing of Arbequina variety (2018 crop) was kindly given by Oliduero (Medina del Campo, Spain). Detailed characterization of the initial raw material is presented in Table 6 . Moisture was determined by drying the material at $105^{\circ} \mathrm{C}$ until stable weight. Fat and extractives were defined by 3 consecutive extractions in Soxhlet using 3 different solvents: $n$-hexane for $6 \mathrm{~h}$ (fat), and $\mathrm{EtOH}$ and water for ca. $18 \mathrm{~h}$ each (extractives). Protein content was determined by the Kjeldahl method (with a conversion factor of 6.25). The ash content corresponded to the char formed at $550{ }^{\circ} \mathrm{C}$. All yield compositions are expressed per gram of dry OP.

Table 6. Olive pomace (OP) characterization.

\begin{tabular}{ccccc}
\hline Moisture & Fat & Ash & Protein & Extractives \\
\hline $\mathbf{g}_{\text {H2O }} / \mathbf{g}_{\text {DRY OP }}$ & $\mathbf{m g} / \mathbf{g}_{\text {DRY OP }}$ & $\mathbf{m g} / \mathbf{g}_{\text {DRY OP }}$ & $\mathbf{m g} / \mathbf{g}_{\text {DRY OP }}$ & $\mathbf{m g} / \mathbf{g}_{\text {DRY OP }}$ \\
\hline $1.48 \pm 0.01$ & $200 \pm 6$ & $25.2 \pm 1.7$ & $143 \pm 4$ & $479 \pm 7$ \\
\hline
\end{tabular}

Four different pretreatment conditions have been tested for the raw material, as presented in Figure 4. Briefly, the fresh material was submitted to extraction upon arrival, without any previous pre-treatment. The rest of the material was then packed in plastic bags of approximately $1 \mathrm{~kg}$ with the use of $\mathrm{N}_{2}$ (to devoid oxygen) and stored at $-20{ }^{\circ} \mathrm{C}$ for 4 months. The de-frozen OP was subjected to extraction directly after de-freezing, without any drying step. The freeze-dried OP was lyophilized under vacuum (18 $\mathrm{kPa})$ and protected from light for $72 \mathrm{~h}$. The dried OP was produced placing the frozen OP at a chamber of $40{ }^{\circ} \mathrm{C}$ for $24 \mathrm{~h}$ for slow drying. The moisture of the fresh and the de-frozen $\mathrm{OP}$ was $59.7 \pm 0.2 \%\left(1.48 \pm 0.01 \mathrm{~g}_{\mathrm{H}_{2} \mathrm{O}} / \mathrm{g}_{\mathrm{DRY}} \mathrm{OP}\right)$ (Table 6$)$. The freeze-dried and the dried material had ca. $3 \%$ and $45 \%$ of moisture, respectively, and were also subjected to extraction directly after the pretreatment took place. Then, they were stored at room temperature, protected from light and moisture for up to 6 months.

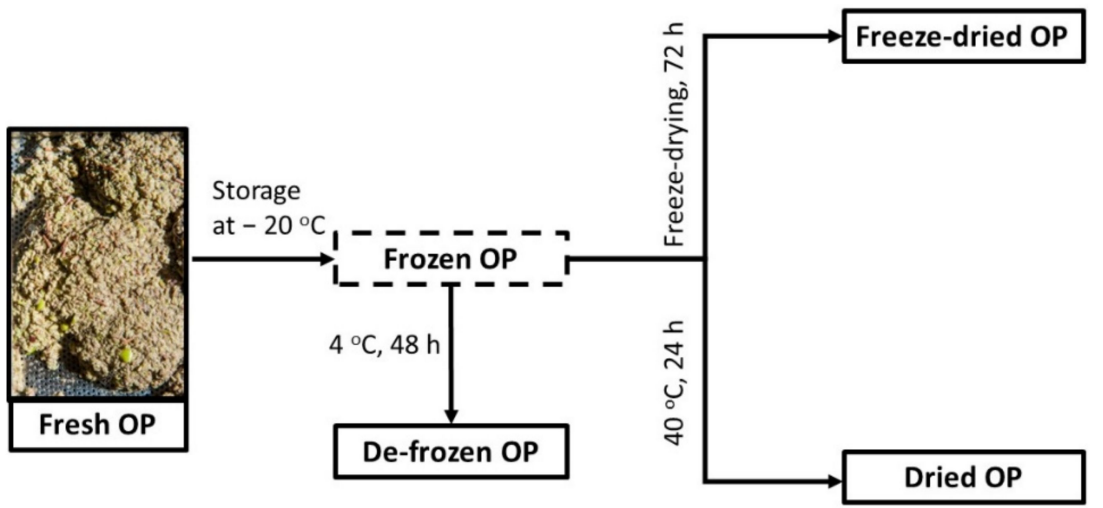

Figure 4. Four different storage conditions of the olive pomace (OP).

\subsection{Materials, Reagents and Solvents}

Milli-Q water was obtained from a Millipore unit. EtOH non denaturalized (99.9\%) was bought from Dávila Villalobos S.L. (Valladolid, Spain), $\mathrm{N}_{2}$ (99.996\%) from Linde Gas (Puçol, Spain), Fluorescein sodium salt from Vetec Química (Xerem Duque De Caxias, Rio de Janeiro, Brazil) and OxiSelect 96-Well Comet Assay Kit from bioNova scientific (Fremont, CA, USA). Methanol (MeOH, 99.9\% LC-MS), $n$-hexane $(95 \%), \mathrm{NaOH}$ pellets, Dimethyl Sulfoxide (DMSO), and phosphoric acid were supplied by Panreac Quimica SLU (Barcelona, Spain), while commercial standards HT ( $\geq 98 \%)$, TY $(\geq 99 \%)$ and $\mathrm{OL}\left(\geq 98 \%\right.$ ) by Extrasynthese (Genay, France). $\mathrm{MgSO}_{4}$ anhydrous, $\mathrm{KI}, \mathrm{NaBr}, \mathrm{NaCl}$, Trolox (6-hydroxy-2,5,7,8-tetramethylchromane-2-carboxylic acid), AAPH (2,2'-azobis(2methylpropionamidine)dihydrochloride), gallic acid, catechin, Tris-EDTA buffer solution, 
and bovine insulin were purchased from Sigma-Aldrich (Madrid, Spain). Plastic culture flasks, plates, tips, and pipettes, Dulbecco's modified Eagle's medium/nutrient mixture F-12 (DMEM/F-12) + GlutaMax, Dulbecco's phosphate-buffered saline, fetal bovine serum, human epithelial growth factor, human insulin, penicillin, and streptomycin were supplied by Thermo Fisher Scientific (Rockford, IL, USA). CO 2 (99.95\%) was obtained by Carburos Metálicos (Barcelona, Spain).

\subsection{Phenolic Extraction}

The experimental scheme regarding the phenolic extraction of the differently stored and pre-treated OP is presented in Figure 5. The experimental procedure for each step is described below in detail.

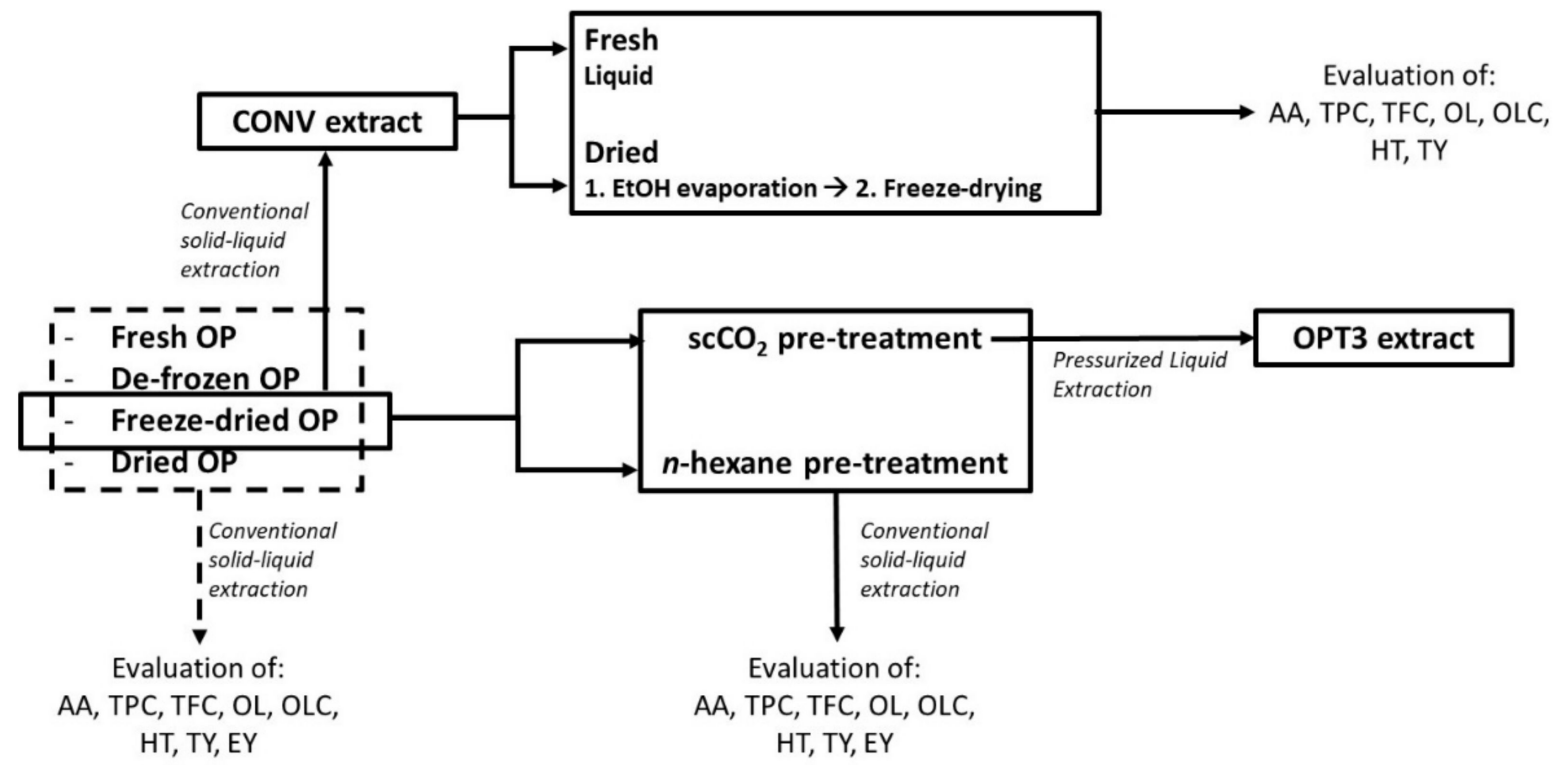

Figure 5. Experimental procedure followed for the phenolic extraction of the differently pretreated olive pomace (OP) and the effect of the extract drying. All extracts were evaluated in terms of antioxidant activity (AA) and richness in total phenolic content (TPC), total flavonoid content (TFC), oleuropein (OL), oleacein (OLC), hydroxytyrosol (HT), and tyrosol (TY). The extracts derived by the differently pretreated OP were also evaluated in terms of extraction yield (EY).

\subsubsection{Conventional Process: Effect of Different Pretreatment Conditions}

To study the effect of the pretreatment conditions on the raw material, all materials (fresh, de-frozen, freeze-dried, or dried) were subjected to the same conventional solidliquid phenolic extraction. The conditions were selected based on industrial constraints (principally solvent consumption) according to Álvarez [12] and Katsinas et al. [16], who also describe the extraction process in detail. Briefly, the CONV extract was produced using freeze-dried OP without any additional pre-treatment and applying a $\mathrm{T}$ of $70.0^{\circ} \mathrm{C}$, a $\%$ EtOH of $50.0 \%$, and a solid/liquid ratio (S/L) of 0.5 g RAW OP $/ \mathrm{mL}_{\text {SOLVENT }}$. The same extraction process and conditions were applied to all the differently pretreated OP. All extractions were performed in triplicate.

\subsubsection{Conventional Process: Defatting Pretreatment Step Selection}

Two different defatting methods were applied to the freeze-dried OP: a conventional one using $n$-hexane and a $\mathrm{scCO}_{2}$ extraction. The conditions used for each process have been selected considering industrial constraints and are described by Katsinas et al. [16]. The percentage of the yield of the oil obtained was calculated gravimetrically by weighing the OP before and after the process. Both defatting processes were performed in triplicate. Following this, the two differently defatted OP were subjected to a conventional 
solid-liquid phenolic extraction as previously described. Phenolic extractions were also performed in triplicate.

\subsubsection{PLE Process}

For the preparation of the OPT3 extract, the freeze-dried OP was defatted with $\mathrm{scCO}_{2}$ and then, a PLE extraction was performed, according to conditions previously optimized [16], to obtain an extract enriched in HT, TY, and TPC. Thus, a T of $184.0^{\circ} \mathrm{C}$, a $\%$ EtOH of $90.0 \%$, and a S/L of 0.8 gRAW OP $/ \mathrm{mLSOLVENT}_{\text {Tere }}$ used.

All phenolic extracts remained in liquid form after production and were stored in darkness and at $-20{ }^{\circ} \mathrm{C}$ until analysis.

\subsection{Extract Drying}

The effect of the drying process on the produced extract has been studied using the CONV extract (Figure 5). After the extraction, part of CONV was kept in liquid form (reference) and the rest was dried in two sequential steps. Briefly, CONV was transferred to a round bottom flask and, using a rotary evaporator (Buchi Rotavapor R-200, Flawil, Switzerland), the $\mathrm{EtOH}$ was evaporated at $60^{\circ} \mathrm{C}$ and ca. $20 \mathrm{kPa}$ (step 1) for approximately $20 \mathrm{~min}$. The extract containing principally water was lyophilized under vacuum (18 kPa) and in darkness for $72 \mathrm{~h}$ (Lyoquest-55, Telstar, Terrassa, Spain) (step 2). The liquid sample after step 1 was filtered using a $0.20 \mu \mathrm{m}$ polyvinylidene fluoride filter to remove any residual soil. The final dried extract (after step 2) was reconstituted in $\mathrm{EtOH}: \mathrm{H}_{2} \mathrm{O}=50: 50$ at $5.0 \mathrm{mg} / \mathrm{mL}$ and filtered similarly. Both samples were characterized together with the freshly prepared liquid extract (reference). From the already determined EY of the CONV extract, all results were calculated and expressed as $\mathrm{mg}$ of compound/compound equivalents or mmol of TE (for AA) per $g$ of DE. The procedure was performed in duplicate.

\subsection{Extract Characterization: Pretreatment Effect, Defatting Process and Extract Drying}

The extracts produced by the differently pretreated or defatted OP were characterized in terms of EY, TPC, TFC, AA (determined by the ORAC assay), and richness in major phenolic compounds (HT, OL, TY, and OLC) (Figure 5). The differently dried extracts were reconstituted (ca. $5.0 \mathrm{mg} / \mathrm{mL}$ ) and were characterized similarly, except the EY. The procedures followed for all the aforementioned characterizations are described in detail by Katsinas et al. [16] The richness in HT, OL, TY, and OLC was determined by HPLC-DAD as described below. The results for EY are expressed as $\mathrm{mg}$ of DE/g of dry OP, for TPC as $\mathrm{mg}$ of gallic acid equivalents (GAE)/g DE, for TFC as mg of catechin equivalents (CATE)/g DE, and for AA as mmol of Trolox equivalents (TE)/g DE. The extract richness in the selected phenolic compounds is expressed as mg of compounds/g DE. OLC was calculated as OL equivalents (OLE).

\subsection{HPLC-DAD Analysis}

The quantitative determination of HT, TY, and OL was performed by an HPLCDAD system: Waters e2695 separation module with an autosampler $(20 \mu \mathrm{L}$ injection volume) and a quaternary pump, coupled with Waters 2998 photodiode array detector set at $280 \mathrm{~nm}$ (Waters ${ }^{\circledR}$, Dublin, Ireland). A C18 Mediterranean Sea column $(250 \times 4.6 \mathrm{~mm}$, $5 \mu \mathrm{m})$ (Teknokroma Analítica S.A., Barcelona, Spain) at $35^{\circ} \mathrm{C}$ connected with an OptiGuard $1 \mathrm{~mm}$ guard column (Sigma-Aldrich, St. Louis, MO, USA) were used. The gradient method, together with the eluents and the elution program used, were selected according to Katsinas et al. [16]. Calibration curves for OL (range: $12.5-1250 \mathrm{mg} / \mathrm{L}$, linearity: $R^{2}=0.9989$ ), HT (range: $25-300 \mathrm{mg} / \mathrm{L}$, linearity: $R^{2}=0.9992$ ), and TY (range: $12.2-200 \mathrm{mg} / \mathrm{L}$, linearity: $\left.\mathrm{R}^{2}=0.9969\right)$ were prepared, using standard solutions of the compounds in DMSO, and analyzed in the same conditions as the samples. Compounds in the extracts were identified by comparing the retention time and the UV spectra of the samples with those of the standard solutions, while MS spectra were also used to confirm identification (see Section 3.7.1 for experimental conditions). The accuracy was determined 
as the level of agreement between the results of analysis of 3 independent analyte samples of known concentration and the true value. It was expressed as \% relative error \pm standard deviation (SD) among the independent samples and calculated as $-1.6 \pm 0.8 \%$ for OL, $-4.7 \pm 3.8 \%$ for HT, and $-3.3 \pm 2.8 \%$ for TY. The precision/repeatability was determined as the degree of agreement among 3 individual test results of the same analyte sample and was calculated as 3.2\% relative SD for OL, 2.2\% for HT, and $6.8 \%$ for TY. Samples and calibration curves of standard solutions were analyzed within the same day. For the 6-months storage stability, relative quantification was performed with respect to the initial quantity $\mathrm{t}_{0}$ of each analyte. For data acquisition and processing, Empower ${ }^{\circledR} 3$ software (Waters ${ }^{\circledR}$, Dublin, Ireland) was used.

3.7. Composition, Stability and Genotoxicity Characterization towards Ophthalmic Applications of Aqueous Solutions of Selected Extracts (CONV, OPT3) and Pure Compounds (HT and OL)

\subsubsection{HPLC-DAD-MS/MS Analysis}

The phenolic compounds present in the freshly prepared aqueous solutions of CONV and OPT3, and the degradation phenolic products present in the $40{ }^{\circ} \mathrm{C}$ exposed aqueous solutions of OL, HT, CONV, and OPT3, were putatively identified by an HPLC-DAD-MS/MS system: Waters Alliance 2695 (Waters ${ }^{\circledR}$, Dublin, Dublin, Ireland) separation module with an autosampler (10 $\mu \mathrm{L}$ injection volume), a quaternary pump and a solvent degasser, coupled to a Photodiode Array Detector Waters 996 PDA (Waters ${ }^{\circledR}$, Dublin, Ireland) scanning wavelength absorption between 210 and $600 \mathrm{~nm}$. A LiChrospher ${ }^{\circledR} 100 \mathrm{RP}-185 \mu \mathrm{m}$ $(250 \times 4.0 \mathrm{~mm})$ (Sigma-Aldrich, St. Louis, MO, USA) column at $35^{\circ} \mathrm{C}$ (stabilized by a column oven) was used. MS/MS detection was carried out with a Micromass ${ }^{\circledR}$ Quattro Micro triple quadrupole (Waters ${ }^{\circledR}$, Dublin, Ireland), using an ESI. A full scan mode $(\mathrm{m} / \mathrm{z}$ : 60-1100) record was applied for the mass spectra of the compounds separated by HPLC, using a collision energy of $20 \mathrm{eV}$. The HPLC gradient method, eluents, and elution program used, together with the source temperature, capillary, and source voltages are described by Katsinas et al. [16] For data acquisition and processing, MassLynx ${ }^{\circledR} 4.1$ software (Waters ${ }^{\circledR}$, Dublin, Ireland) was used.

\subsubsection{In vitro genotoxicity Assay \\ Cell Culture}

Two different ocular surface epithelial cell lines were used for the genotoxicity assays: the HCE and the IM-ConjEpi.

HCE is an immortalized human corneal epithelial cell line [72], kindly offered by Dr. Arto Urti (University of Helsinki, Finland). It was cultured in DMEM/F-12 + GlutaMax supplemented with $10 \%$ fetal bovine serum, $10 \mathrm{ng} / \mathrm{mL}$ human epithelial growth factor, $5 \mu \mathrm{g} / \mathrm{mL}$ human insulin and antibiotics $(100 \mathrm{U} / \mathrm{mL}$ penicillin $+0.1 \mathrm{mg} / \mathrm{mL}$ streptomycin). IM-ConjEpi was supplied by Innoprot (Derio, Spain. Ref. P10870-IM) and is an SV40- Large T Antigen immortalized human conjunctival epithelial cell line. It was cultured in DMEM/F-12 + GlutaMax supplemented with $10 \%$ fetal bovine serum, $10 \mathrm{ng} / \mathrm{mL}$ human epithelial growth factor, $1 \mu \mathrm{g} / \mathrm{mL}$ bovine insulin and antibiotics $(5000 \mathrm{U} / \mathrm{mL}$ penicillin $+5000 \mu \mathrm{g} / \mathrm{mL}$ streptomycin). HCE cell line was used from passage 25 to 35 , while IM-ConjEpi from passage 10 to 20.

The cells were incubated at $37^{\circ} \mathrm{C}$ and 5:95 $=\mathrm{CO}_{2}$ :air atmosphere ratio, while their medium was changed every second day. Observations through a phase-contrast microscope were carried out daily.

\section{Preparation of Treatment Phenolic Solutions}

For the in vitro tests, $\mathrm{HT}, \mathrm{OL}, \mathrm{CONV}$, and OPT3 were dissolved in culture medium (DMEM/F-12 + GlutaMax, without any supplement) the day of the experiment. As previously described, CONV was produced by conventional solid-liquid extraction using freeze-dried material without any further pretreatment. OPT3 was generated by PLE extraction using freeze-dried material previously defatted with $\mathrm{scCO}_{2}$. The part of the 
extracts not dissolved to the culture medium was filtered through a $0.20 \mu \mathrm{m}$ polyvinylidene fluoride sterile filter. The in vitro concentrations were selected according to a previous study, which described the maximum allowable non-toxic concentration of HT, OL, CONV, and OPT3 on the two ocular surface cell lines used [17]. Thus, HT was tested at a concentration of $100 \mu \mathrm{M}$ (equivalent to $15.4 \mathrm{mg} / \mathrm{L}$ ), $\mathrm{OL}$ at $300 \mu \mathrm{M}$ (equivalent to $162.2 \mathrm{mg} / \mathrm{L}$ ), CONV at $80 \mathrm{mg} / \mathrm{L}$ and OPT3 at $40 \mathrm{mg} / \mathrm{L}$. A mixture of $5 \mu \mathrm{M}$ of OL $(2.7 \mathrm{mg} / \mathrm{L})$ with $50 \mu \mathrm{M}$ of HT $(7.7 \mathrm{mg} / \mathrm{L})$ was prepared by mixing the double concentration of each compound in equal volumes.

\section{Comet Assay}

To test the in vitro genotoxicity effect of the phenolic solutions, the comet assay was selected. The protocol was performed on HCE and IM-ConjEpi cells as previously described by Di Mauro et al. [73], with some modifications. According to the manufacturer's instructions, the cells mixed with liquid agarose were placed on an agarose-precoated 96-well slide and left at $4{ }^{\circ} \mathrm{C}$ for $15 \mathrm{~min}$ until solidification. Then, the slide was immersed in lysis buffer (2.5 M NaCl, $100 \mathrm{mM} \mathrm{Na2EDTA,} 10 \mathrm{mM}$ Tris-HCl, 1\% N-laurosil-sarcosine, $1 \%$ Triton $\mathrm{X}-100,10 \% \mathrm{DMSO}, \mathrm{pH} 10$ ) at $4{ }^{\circ} \mathrm{C}$ for $60 \mathrm{~min}$. Subsequently, it was transferred to a container filled with pre-chilled alkaline solution ( $300 \mathrm{mM} \mathrm{NaOH}, 1 \mathrm{mM} \mathrm{Na2EDTA}$ ) and left immersed at $4{ }^{\circ} \mathrm{C}$ for $30 \mathrm{~min}$ to allow DNA to unroll. Following this, using the same alkaline solution, alkaline electrophoresis was performed for $30 \mathrm{~min}$ at $1 \mathrm{volt} / \mathrm{cm}$ and $300 \mathrm{~mA}$. Finally, the slide was washed 3 times with pre-chilled distilled $\mathrm{H}_{2} \mathrm{O}$, dried with $70 \%$ ethanol, and stained with vista green DNA dye for 15 min in darkness. Images were acquired with an inverted epi-fluorescence microscope (DMI 6000 B, Leica, Wetzlar, Germany) using a fluorescein isothiocyanate filter. The images were analyzed using the CASP (1.2.3) image analysis software. Three independent experiments were performed, analyzing ca. 50 cells/treatment for each experiment. Results are expressed as mean of $\%$ TDNA \pm SD.

\subsubsection{Long-Term Storage Stability}

The experimental procedure of the relative stability studies is presented in Figure 6. Briefly, all compounds and extracts were dissolved in Milli-Q water, as high mineralization could increase the degradation of these substances [68]. Additionally, according to the bibliography [68], lower concentrations could accelerate the decomposition of a compound. Hence, higher concentrations have been selected to be measured for all compounds and extracts. CONV and OPT3 were prepared at a concentration of $5.0 \mathrm{mg} / \mathrm{mL}, \mathrm{HT}$ at $72 \mathrm{mg} / \mathrm{L}$, and OL at $113 \mathrm{mg} / \mathrm{L}$. All solutions were filtered through a $0.20 \mu \mathrm{m}$ polyvinylidene fluoride filter. A total of $3 \mathrm{~mL}$ of each phenolic aqueous solution was added to amber glass vials, degassed with $\mathrm{N}_{2}$, closed airtight with a rubber stopper, and sealed with aluminum capsules. To fix the desired humidity for each temperature, appropriate salts have been used according to the bibliography [74]. For $5{ }^{\circ} \mathrm{C}$, the $\mathrm{MgSO}_{4}$ anhydrous was selected (to achieve no humidity), for $25^{\circ} \mathrm{C}: \mathrm{NaBr}$ (to reach a $57.57 \% \pm 0.40 \mathrm{RH}$ ), for $30{ }^{\circ} \mathrm{C}$ : $\mathrm{KI}$ (setting the $\mathrm{RH}$ at $67.89 \% \pm 0.3$ ) and for $40{ }^{\circ} \mathrm{C}: \mathrm{NaCl}$ (establishing an $\mathrm{RH}$ of $74.68 \% \pm 0.13$ ). The vials were placed in big glass containers, together with a sufficient quantity of each salt. Then, they were closed airtight and left in different rooms of controlled temperature and protected from light for 6 months. Samples were taken immediately after preparation (considered as $\mathrm{t}_{0}$ ) and afterward at days 1 (24 h), 2, 4, 6, 8, 10, 12, 14, and 30 (1 month). After the first month, one sample was taken every 30 days, up to a total duration of 6 months. For CONV, HT and OL content were measured, while for OPT3 only HT content was calculated due to the lack of OL in this extract. All samples were analyzed in triplicate and the results are expressed as mean of the percentage with respect to the initial concentration $t_{0} \pm$ SD. 


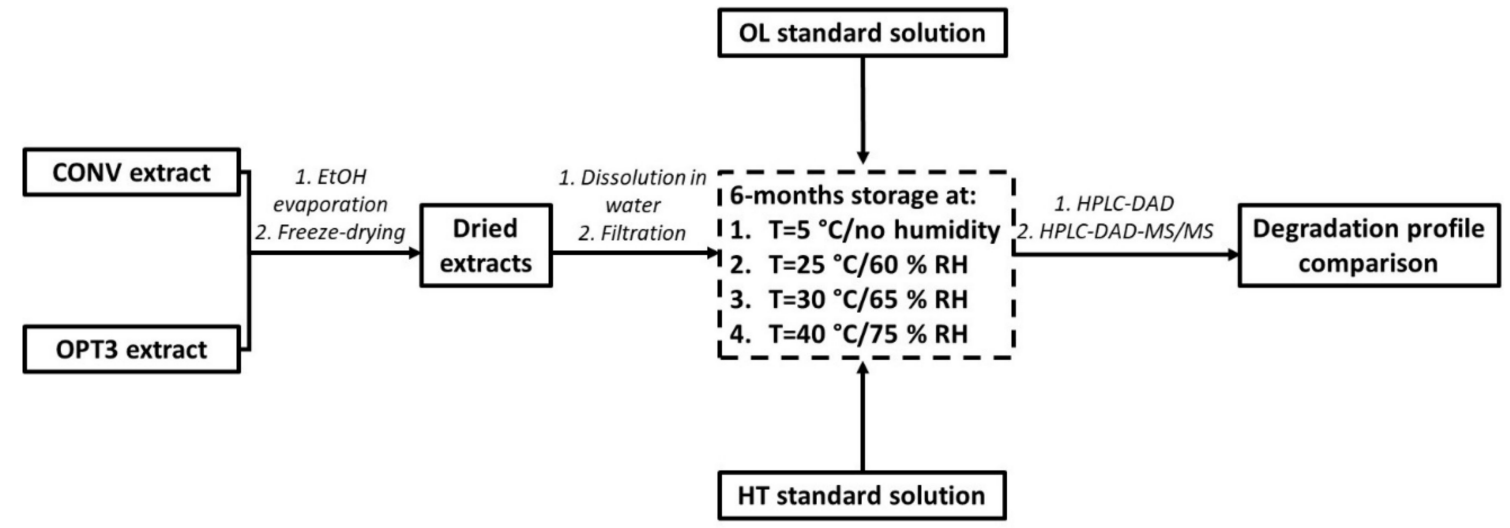

Figure 6. Experimental procedure of the stability studies performed for aqueous solutions of oleuropein (OL) and hydroxytyrosol (HT) standards, as well as of conventional (CONV) and optimized (OPT3) extracts at 4 different conditions of temperature $(\mathrm{T})$ and relative humidity $(\mathrm{RH})$.

\subsection{Statistical Analysis}

Levene's test was used to examine the homogeneity of variances, while one-way ANOVA with Tukey's or Games-Howell post hoc test was performed for intergroup comparisons. For the in vitro results, ROUT analysis was used to identify possible outliers. $p$-values lower than 0.05 were determined as statistically significant. For the statistical analysis, the SPSS software (SPSS 15.0; SPSS, Inc., Chicago, IL, USA) was used, while for kinetics data treatment the Microsoft Excel software (MS Excel 10.0; Microsoft, Redmond, WA, USA) was used.

\section{Conclusions}

The results of this study demonstrate how a usually discarded and potentially environmentally hazardous agro-industrial by-product, the OP, can be transformed into a future ophthalmic product, which is usually aqueous-based. Different pretreatment conditions were evaluated for the raw material in terms of their effect on the richness of its major phenolic compounds in the hydroalcoholic extracts produced. The lyophilization of the raw material and the subsequent $\mathrm{scCO}_{2}$ extraction of the residual oil were proved to be the most suitable. Subsequently, following the EMA industrial guidelines for a drug product, the ophthalmic safety and the 6-month storage stability of aqueous solutions of pure OL and HT, and two selected OP extracts were evaluated. The selection of the OP extracts (CONV: produced by conventional extraction using freeze-dried material, and OPT3: produced by PLE using scCO $\mathrm{CO}_{2}$-defatted freeze-dried OP) was based on previous in vitro ocular anti-inflammatory and antioxidant activity results and irritation studies. Regarding safety, the genotoxic effect (comet assay) was studied on two different human ocular surface epithelial cell lines, proving the use of all compounds and extracts to be safe at the concentrations tested. Regarding long-term storage stability, OL and HT demonstrated a remarkably different stability profile as pure or extract solutions at the four different temperature/moisture conditions tested. OL in CONV was highly degraded (ca. 50\%) after day 2 in all conditions, while on the contrary as a standard solution was stable for up to 1 month at $25^{\circ} \mathrm{C}$ or below. HT as a pure solution demonstrated good stability only at $5{ }^{\circ} \mathrm{C}$. However, as part of OPT3, HT remained stable or was even increased over time proportionally with the reduction of secoiridoids at all conditions. The same tendency was observed for HT in CONV above $30^{\circ} \mathrm{C}$. An HPLC-DAD-MS/MS analysis of the degraded solutions allowed us to identify the different degradation profiles of OL alone or in the extract. The interactions between OL and HT, and the degradation profile of OL aqueous solutions were established for the first time. Hence, a necessary evaluation baseline for the future approval of OP extracts and their major compounds as ophthalmic products was proposed. Future formulation studies are necessary to increase the stability of the composition in the extract or compounds for its final application. 
Supplementary Materials: The following are available online. Figure S1: Stability studies from 1 to 6 months of OL standard, HT standard, OL and HT in CONV, and HT in OPT3 at 4 different conditions of $\mathrm{T}$ and RH, Figure S2: Full scan mass spectra acquired in ESI- from peaks at retention time $15.91 \mathrm{~min}$ and $18.83 \mathrm{~min}$ detected in the analysis of OL aqueous standard solution after exposure for 2 days at $40 \pm 2{ }^{\circ} \mathrm{C}$ and $75 \pm 5 \% \mathrm{RH}$, and scan chromatogram, Figure S3: UV Chromatogram at $280 \mathrm{~nm}$, scan chromatogram in ESI- and full scan mass spectra from peak at retention time $10.14 \mathrm{~min}$ detected in the analysis of HT aqueous solution after 30 days exposure at $40 \pm 2{ }^{\circ} \mathrm{C}$ and $75 \pm 5 \%$ $\mathrm{RH}$, Table S1: ANOVA of all responses measured for extracts generated by conventional phenolic extraction conditions, using OP stored at different conditions, Table S2: ANOVA of the effect of 2 different defatting methods on the responses measured for extracts generated by conventional phenolic extraction conditions, using freeze-dried OP, Table S3: ANOVA of the effect of the extract drying on the stability of the responses measured compared to a freshly obtained liquid extract (reference), Table S4: ANOVA of the genotoxic effect (alkaline comet assay) of OP extracts $(0.8 \mathrm{mg} / \mathrm{mL}$ CONV and $0.4 \mathrm{mg} / \mathrm{mL}$ OPT3), together with $300 \mu \mathrm{M}(162.2 \mathrm{mg} / \mathrm{L}) \mathrm{OL}, 100 \mu \mathrm{M}(15.4 \mathrm{mg} / \mathrm{L}) \mathrm{HT}$ and their mixture $(5 \mu \mathrm{M} / 2.7 \mathrm{mg} / \mathrm{L}+50 \mu \mathrm{M} / 7.7 \mathrm{mg} / \mathrm{L} \mathrm{OL}+\mathrm{HT})$ on HCE and IM-ConjEpi cells treated for $24 \mathrm{~h}$, compared to control cells (treated with culture medium).

Author Contributions: Conceptualization, N.K., A.E.-d.-S. and S.R.-R.; methodology, N.K., A.E.-d.-S., M.R.B. and S.R.-R.; software, N.K. and S.R.-R.; validation, N.K., A.E.-d.-S., M.R.B. and S.R.-R.; formal analysis, N.K. and S.R.-R.; investigation, N.K. and A.B.d.S.; resources, S.R.-R., A.E.-d.-S. and M.R.B.; data curation, N.K.; writing-original draft preparation, N.K.; writing—review and editing, N.K., A.E.-d.-S., A.B.d.S., M.R.B. and S.R.-R.; visualization, N.K. and S.R.-R.; supervision, A.E.-d.-S. and S.R.-R.; project administration, A.E.-d.-S., M.R.B. and S.R.-R.; funding acquisition, S.R.-R., A.E.-d.-S. and María Jesús González García. All authors have read and agreed to the published version of the manuscript.

Funding: This project has received funding from the European Union's Horizon 2020 research and innovation program under the Marie Skłodowska-Curie Initial Training Network (ITN) "IT-DED ${ }^{3 \text { " }}$ (H2020-MSCA-ITN-2017) grant agreement No. 765608. The authors would like to acknowledge the financial support from Fundação para a Ciência e Tecnologia (FCT) and Portugal 2020 to the Portuguese Mass Spectrometry Network (Rede Nacional de Espectrometria de Massa RNEM; LISBOA 010145 FEDER 402 022125). Soraya Rodriguez Rojo acknowledges the University of Valladolid for her postdoctoral contract.

Institutional Review Board Statement: Not applicable.

Informed Consent Statement: Not applicable.

Data Availability Statement: Not applicable.

Acknowledgments: Special thanks to Michael Stern and Margarita Calonge for their contribution regarding ocular surface pathophysiology, and Georgia Ntasi, Pinelopi Vlachou, and Vincent Brieudes for their support regarding HPLC-DAD analysis.

Conflicts of Interest: The authors declare no conflict of interest.

Sample Availability: Not available.

$\begin{array}{ll}\text { Abbreviations } \\ \text { \%EtOH } & \text { Percentage (\%) of ethanol in water } \\ \% \text { TDNA } & \text { Percentage (\%) of DNA present in the comet tail } \\ \text { AA } & \text { Antioxidant Activity } \\ \text { AAPH } & 2,2^{\prime} \text {-azobis(2-methylpropionamidine)dihydrochloride } \\ \text { ANOVA } & \text { Analysis of Variances } \\ \text { CATE } & \text { Catechin Equivalents } \\ \text { CONV } & \text { Conventional olive pomace extract } \\ \text { DE } & \text { Dry Extract } \\ \text { DMEM/F-12 } & \text { Dulbecco's Modified Eagle's Medium/Nutrient Mixture F-12 } \\ \text { DMSO } & \text { Dimethyl Sulfoxide } \\ \text { EMA } & \text { European Medicines Agency }\end{array}$




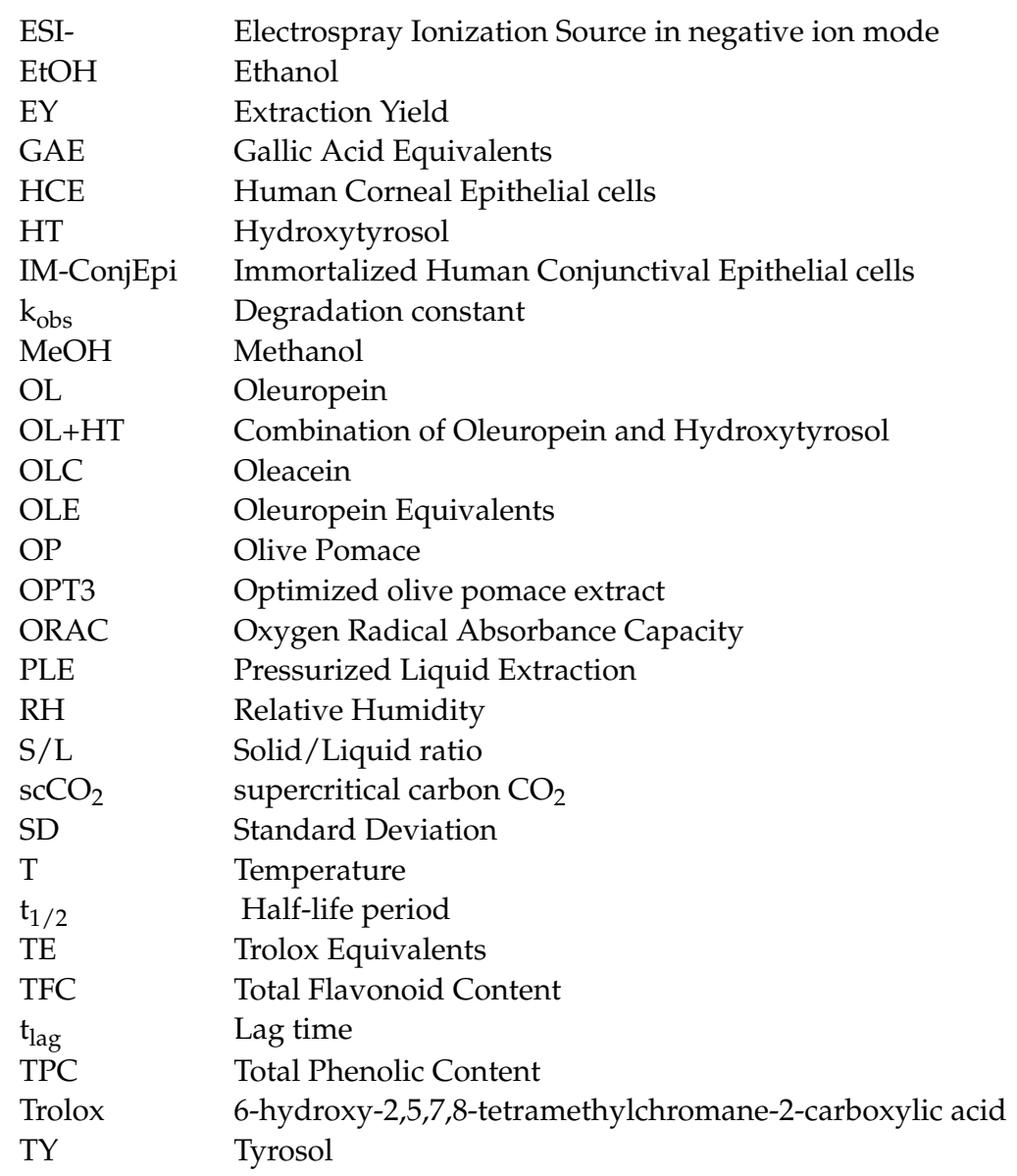

\section{References}

1. FAOSTAT. Available online: http://www.fao.org/home/search/en/?q=Olivemillwastesproduction (accessed on 7 May 2021).

2. Dermeche, S.; Nadour, M.; Larroche, C.; Moulti-Mati, F.; Michaud, P. Olive mill wastes: Biochemical characterizations and valorization strategies. Process. Biochem. 2013, 48, 1532-1552. [CrossRef]

3. Galanakis, C.M. Olive Mill Waste: Recent Advances for the Sustainable Management; Academic Press, Elsevier: London, UK, 2017.

4. Obied, H.K.; Allen, M.S.; Bedgood, D.R.; Prenzler, P.D.; Robards, K.; Stockmann, R. Bioactivity and analysis of biophenols recovered from olive mill waste. J. Agric. Food Chem. 2005, 53, 823-837. [CrossRef] [PubMed]

5. Romero-García, J.M.; Niño, L.; Martínez-Patiño, C.; Álvarez, C.; Castro, E.; Negro, M.J. Biorefinery based on olive biomass. State of the art and future trends. Bioresour. Technol. 2014, 159, 421-432. [CrossRef] [PubMed]

6. Sánchez Moral, P.; Ruiz Méndez, M.V. Production of pomace olive oil. Grasas y Aceites 2006, 57, 47-55. [CrossRef]

7. Kapellakis, I.E.; Tsagarakis, K.P.; Avramaki, C.; Angelakis, A.N. Olive mill wastewater management in river basins: A case study in Greece. Agric. Water Manag. 2006, 82, 354-370. [CrossRef]

8. Niaounakis, M.; Halvadakis, C.P. Waste Management Series: Volume 5-Olive Processing Waste Management, Literature Review and Patent Survey; Elsevier: Amsterdam, The Netherlands, 2006; pp. 65-81.

9. Lozano-Sánchez, J.; Giambanelli, E.; Quirantes-Piné, R.; Cerretani, L.; Bendini, A.; Segura-Carretero, A.; Fernández-Gutiérrez, A. Wastes generated during the storage of extra virgin olive oil as a natural source of phenolic compounds. J. Agric. Food Chem. 2011, 59, 11491-11500. [CrossRef]

10. Obied, H.K.; Bedgood, D.R.; Prenzler, P.D.; Robards, K. Chemical screening of olive biophenol extracts by hyphenated liquid chromatography. Anal. Chim. Acta 2007, 603, 176-189. [CrossRef]

11. Gómez-Cruz, I.; Cara, C.; Romero, I.; Castro, E.; Gullón, B. Valorisation of Exhausted Olive Pomace by an Eco-Friendly Solvent Extraction Process of Natural Antioxidants. Antioxidants 2020, 9, 1010. [CrossRef]

12. Álvarez, A. Development of a Microwave Pretreatment for the Extraction of Active Compounds from Natural by-Products (Chapter 6). Ph.D. Thesis, University of Valladolid (UVa), Valladolid, Spain, 2018.

13. Schievano, A.; Adani, F.; Buessing, L.; Botto, A.; Casoliba, E.N.; Rossoni, M.; Goldfarb, J.L. An integrated biorefinery concept for olive mill waste management: Supercritical CO2 extraction and energy recovery. Green Chem. 2015, 17, 2874-2887. [CrossRef]

14. Xie, P.; Huang, L.; Zhang, C.; Deng, Y.; Wang, X.; Cheng, J. Enhanced extraction of hydroxytyrosol, maslinic acid and oleanolic acid from olive pomace: Process parameters, kinetics and thermodynamics, and greenness assessment. Food Chem. 2019, 276, 662-674. [CrossRef] 
15. Antónia Nunes, M.; Costa, A.S.G.; Bessada, S.; Santos, J.; Puga, H.; Alves, R.C.; Freitas, V.; Oliveira, M.B.P.P. Olive pomace as a valuable source of bioactive compounds: A study regarding its lipid- and water-soluble components. Sci. Total Environ. 2018, 644, 229-236. [CrossRef]

16. Katsinas, N.; Bento da Silva, A.; Enríquez-de-Salamanca, A.; Fernández, N.; Bronze, M.R.; Rodríguez-Rojo, S. Pressurized Liquid Extraction Optimization from Supercritical Defatted Olive Pomace: A Green and Selective Phenolic Extraction Process. ACS Sustain. Chem. Eng. 2021, 9, 5590-5602. [CrossRef]

17. Katsinas, N.; Rodríguez-Rojo, S.; Enríquez-de-Salamanca, A. Olive Pomace Phenolic Compounds and Extracts Can Inhibit Inflammatory- and Oxidative-Related Diseases of Human Ocular Surface Epithelium. Antioxidants 2021, 10, 1150. [CrossRef]

18. Di Mauro, M.D.; Fava, G.; Spampinato, M.; Aleo, D.; Melilli, B.; Saita, M.G.; Centonze, G.; Maggiore, R.; D'antona, N. Polyphenolic fraction from olive mill wastewater: Scale-up and in vitro studies for ophthalmic nutraceutical applications. Antioxidants 2019, 8, 462. [CrossRef]

19. Wakamatsu, T.H.; Dogru, M.; Matsumoto, Y.; Kojima, T.; Kaido, M.; Ibrahim, O.M.A.; Sato, E.A.; Igarashi, A.; Ichihashi, Y.; Satake, Y.; et al. Evaluation of lipid oxidative stress status in Sjögren syndrome patients. Investig. Ophthalmol. Vis. Sci. 2013, 54, 201-210. [CrossRef]

20. Dogru, M.; Kojima, T.; Simsek, C.; Tsubotav, K. Potential role of oxidative stress in ocular surface inflammation and dry eye disease. Investig. Ophthalmol. Vis. Sci. 2018, 59, DES163-DES168. [CrossRef]

21. Calonge, M.; Enríquez-de-Salamanca, A.; Diebold, Y.; González-García, M.J.; Reinoso, R.; Herreras, J.M.; Corell, A. Dry Eye Disease as an Inflammatory Disorder. Ocul. Immunol. Inflamm. 2010, 18, 244-253. [CrossRef] [PubMed]

22. Ward, S.K.; Wakamatsu, T.H.; Dogru, M.; Ibrahim, O.M.A.; Kaido, M.; Ogawa, Y.; Matsumoto, Y.; Igarashi, A.; Ishida, R.; Shimazaki, J.; et al. The role of oxidative stress and inflammation in conjunctivochalasis. Investig. Ophthalmol. Vis. Sci. 2010, 51, 1994-2002. [CrossRef] [PubMed]

23. Wakamatsu, T.H.; Dogru, M.; Ayako, I.; Takano, Y.; Matsumoto, Y.; Ibrahim, O.M.A.; Okada, N.; Satake, Y.; Fukugawa, K.; Shimazaki, J.; et al. Evaluation of lipid oxidative stress status and inflammation in atopic ocular surface disease. Mol. Vis. 2010, 16, 2465-2475. [CrossRef] [PubMed]

24. Ghanbari Shendi, E.; Sivri Ozay, D.; Ozkaya, M.T.; Ustunel, N.F. Changes occurring in chemical composition and oxidative stability of virgin olive oil during storage. OCL-Oilseeds Fats Crop. Lipids 2018, 25, A602. [CrossRef]

25. Britton, J.; Davis, R.; O'Connor, K.E. Chemical, physical and biotechnological approaches to the production of the potent antioxidant hydroxytyrosol. Appl. Microbiol. Biotechnol. 2019, 103, 5957-5974. [CrossRef] [PubMed]

26. Yuan, J.J.; Wang, C.Z.; Ye, J.Z.; Tao, R.; Zhang, Y.S. Enzymatic hydrolysis of oleuropein from Olea europea (olive) leaf extract and antioxidant activities. Molecules 2015, 20, 2903-2921. [CrossRef] [PubMed]

27. Farrés-Cebrián, M.; Seró, R.; Saurina, J.; Núñez, O. HPLC-UV Polyphenolic Profiles in the Classification of Olive Oils and Other Vegetable Oils via Principal Component Analysis. Separations 2016, 3, 33. [CrossRef]

28. Carranco, N.; Farrés-Cebrián, M.; Saurina, J.; Núñez, O. Authentication and Quantitation of Fraud in Extra Virgin Olive Oils Based on HPLC-UV Fingerprinting and Multivariate Calibration. Foods 2018, 7, 44. [CrossRef] [PubMed]

29. Krichene, D.; Allalout, A.; Mancebo-Campos, V.; Salvador, M.D.; Zarrouk, M.; Fregapane, G. Stability of virgin olive oil and behaviour of its natural antioxidants under medium temperature accelerated storage conditions. Food Chem. 2010, 121, 171-177. [CrossRef]

30. Krichene, D.; Salvador, M.D.; Fregapane, G. Stability of Virgin Olive Oil Phenolic Compounds during Long-Term Storage (18 Months) at Temperatures of 5-50 ${ }^{\circ} \mathrm{C}$. J. Agric. Food Chem. 2015, 63, 6779-6786. [CrossRef]

31. Alonso-Salces, R.M.; Gallo, B.; Collado, M.I.; Sasía-Arriba, A.; Viacava, G.E.; García-González, D.L.; Gallina Toschi, T.; Servili, M.; Berrueta, L.Á. 1H-NMR fingerprinting and supervised pattern recognition to evaluate the stability of virgin olive oil during storage. Food Control. 2021, 123, 107831. [CrossRef]

32. Ahmad-Qasem, M.H.; Ahmad-Qasem, B.H.; Barrajón-Catalán, E.; Micol, V.; Cárcel, J.A.; García-Pérez, J.V. Drying and storage of olive leaf extracts. Influence on polyphenols stability. Ind. Crops Prod. 2016, 79, 232-239. [CrossRef]

33. European Medicines Agency. ICH Topic Q 1 A (R2) Stability Testing of new Drug Substances and Products Step 5 NOTE FOR GUIDANCE ON STABILITY TESTING: STABILITY TESTING OF NEW DRUG SUBSTANCES AND PRODUCTS; European Medicines Agency: Amsterdam, The Netherlands, 2003.

34. GRAS Notice 876, Hydroxytyrosol; Nova Mentis: Dublin, Ireland, 2019.

35. Turck, D.; Bresson, J.; Burlingame, B.; Dean, T.; Fairweather-Tait, S.; Heinonen, M.; Hirsch-Ernst, K.I.; Mangelsdorf, I.; McArdle, H.J.; Naska, A.; et al. Safety of hydroxytyrosol as a novel food pursuant to Regulation (EC) No 258/97. EFSA J. 2017, 15. [CrossRef]

36. COMMISSION IMPLEMENTING DECISION (EU) 2017/2373-Of 14 December 2017-Authorising the placing on the market of hydroxytyrosol as a novel food ingredient under Regulation (EC) No 258/97 of the European Parliament and of the Council(notified under document number C (2017) 8423). (Only the Spanish text is authentic). OJ L 2017, 337, 56-59.

37. British Pharmacopoeia; Medicines and Healthcare Products Regulatory Agency: London, UK, 2021.

38. The United States Pharmacopeia; United States Pharmacopeial Convention: Rockville, MD, USA, 2019.

39. European Pharmacopeia, 10th ed.; European Pharmacopoeia Commission; European Directorate for the Quality of Medicines \& Healthcare: Strasbourg, France, 2020. 
40. European Medicines Agency. ICH Guideline S2 (R1) on Genotoxicity Testing and Data Interpretation for Pharmaceuticals Intended for Human Use; European Medicines Agency: Amsterdam, The Netherlands, 2012.

41. Tomasello, B.; Malfa, G.; Galvano, F.; Renis, M. DNA damage in normal-weight obese syndrome measured by Comet assay. Med. J. Nutr. Metab. 2011, 4, 99-104. [CrossRef]

42. Viner, K.J.; Champagne, P.; Jessop, P.G. Comparison of cell disruption techniques prior to lipid extraction from Scenedesmus sp. slurries for biodiesel production using liquid CO2. Green Chem. 2018, 20, 4330-4338. [CrossRef]

43. Kot, A.M.; Gientka, I.; Bzducha-Wróbel, A.; Błażejak, S.; Kurcz, A. Comparison of simple and rapid cell wall disruption methods for improving lipid extraction from yeast cells. J. Microbiol. Methods 2020, 176, 105999. [CrossRef] [PubMed]

44. Kröger, M.; Klemm, M.; Nelles, M. Extraction behavior of different conditioned S. Rubescens. Energies 2019, 12. [CrossRef]

45. Sarikaki, G.; Christoforidou, N.; Gaboriaud-Kolar, N.; Smith, A.B.; Kostakis, I.K.; Skaltsounis, A.L. Biomimetic Synthesis of Oleocanthal, Oleacein, and Their Analogues Starting from Oleuropein, A Major Compound of Olive Leaves. J. Nat. Prod. 2020, 83, 1735-1739. [CrossRef] [PubMed]

46. Jiao, Y.; Li, D.; Chang, Y.; Xiao, Y. Effect of Freeze-Thaw Pretreatment on Extraction Yield and Antioxidant Bioactivity of Corn Carotenoids (Lutein and Zeaxanthin). J. Food Qual. 2018, 2018, 1-8. [CrossRef]

47. Zhao, S.; Baik, O.-D.; Choi, Y.J.; Kim, S.-M. Pretreatments for the Efficient Extraction of Bioactive Compounds from Plant-Based Biomaterials. Crit. Rev. Food Sci. Nutr. 2014, 54, 1283-1297. [CrossRef]

48. Zorić, Z.; Pelaić, Z.; Pedisić, S.; Elez Garofulić, I.; Bursać Kovačević, D.; Dragović-Uzelac, V. Effect of storage conditions on phenolic content and antioxidant capacity of spray dried sour cherry powder. LWT-Food Sci. Technol. 2017, 79, 251-259. [CrossRef]

49. Lang, G.H.; Lindemann, I. da S.; Ferreira, C.D.; Hoffmann, J.F.; Vanier, N.L.; de Oliveira, M. Effects of drying temperature and long-term storage conditions on black rice phenolic compounds. Food Chem. 2019, 287, 197-204. [CrossRef]

50. Goel, M.; Picciani, R.G.; Lee, R.K.; Bhattacharya, S.K. Aqueous Humor Dynamics: A. Review. Open, J. Ophthalmol. 2010, 4, 52-59. [CrossRef] [PubMed]

51. Prashar, A. Shed Tears for Diagnostics. In Tear Cocktail: Composition of Tears; Springer: Singapore, 2019; pp. 21-49.

52. Donnenfeld, E.; Pflugfelder, S.C. Topical Ophthalmic Cyclosporine: Pharmacology and Clinical Uses. Surv. Ophthalmol. 2009, 54, 321-338. [CrossRef] [PubMed]

53. Lallemand, F.; Felt-Baeyens, O.; Besseghir, K.; Behar-Cohen, F.; Gurnya, R. Cyclosporine A delivery to the eye: A pharmaceutical challenge. Eur. J. Pharm. Biopharm. 2003, 56, 307-318. [CrossRef]

54. Attard, T.M.; Bukhanko, N.; Eriksson, D.; Arshadi, M.; Geladi, P.; Bergsten, U.; Budarin, V.L.; Clark, J.H.; Hunt, A.J. Supercritical extraction of waxes and lipids from biomass: A valuable first step towards an integrated biorefinery. J. Clean. Prod. 2018, 177, 684-698. [CrossRef]

55. Tirado, D.F.; de la Fuente, E.; Calvo, L. A selective extraction of hydroxytyrosol rich olive oil from alperujo. J. Food Eng. 2019, 263, 409-416. [CrossRef]

56. Sólyom, K.; Solá, R.; Cocero, M.J.; Mato, R.B. Thermal degradation of grape marc polyphenols. Food Chem. 2014, 159, 361-366. [CrossRef] [PubMed]

57. Moreno, T.; Cocero, M.J.; Rodríguez-Rojo, S. Storage stability and simulated gastrointestinal release of spray dried grape marc phenolics. Food Bioprod. Process. 2018, 112, 96-107. [CrossRef]

58. Lamuela-Raventós, R.M. Folin-Ciocalteu method for the measurement of total phenolic content and antioxidant capacity. Meas. Antioxid. Act. Capacit. Recent Trends Appl. 2017, 107-115. [CrossRef]

59. Quirantes-Piné, R.; Lozano-Sánchez, J.; Herrero, M.; Ibáñez, E.; Segura-Carretero, A.; Fernández-Gutiérrez, A. HPLC-ESI-QTOFMS as a powerful analytical tool for characterising phenolic compounds in olive-leaf extracts. Phytochem. Anal. 2013, 24, 213-223. [CrossRef]

60. Contreras, M.d.M.; Gómez-Cruz, I.; Romero, I.; Castro, E. Olive Pomace-Derived Biomasses Fractionation through a Chemical Characteristics. Foods 2021, 10, 111.

61. Tóth, G.; Alberti, Á.; Sólyomváry, A.; Barabás, C.; Boldizsár, I.; Noszál, B. Phenolic profiling of various olive bark-types and leaves: HPLC-ESI/MS study. Ind. Crops Prod. 2015, 67, 432-438. [CrossRef]

62. Napolitano, A.; De Lucia, M.; Panzella, L.; d'Ischia, M. The Chemistry of Tyrosol and Hydroxytyrosol: Implications for Oxidative Stress. Olives and Olive Oil in Health and Disease Prevention; Elsevier: Amsterdam, The Netherlands, 2010. [CrossRef]

63. Cayman Chemical Company. Oleuropein—Product Information Sheet, Item No. 21220; Cayman Chemical Company: Ann Arbor, MA, USA, 2017.

64. Singh, N.P.; McCoy, M.T.; Tice, R.R.; Schneider, E.L. A simple technique for quantitation of low levels of DNA damage in individual cells. Exp. Cell Res. 1988, 175, 184-191. [CrossRef]

65. Pu, X.; Wang, Z.; Klaunig, J.E. Alkaline comet assay for assessing DNA damage in individual cells. Curr. Protoc. Toxicol. 2015, 65, 3-12. [CrossRef] [PubMed]

66. Lozano-Sánchez, J.; Bendini, A.; Quirantes-Piné, R.; Cerretani, L.; Segura-Carretero, A.; Fernández-Gutiérrez, A. Monitoring the bioactive compounds status of extra-virgin olive oil and storage by-products over the shelf life. Food Control. 2013, 30, 606-615. [CrossRef] 
67. Attya, M.; Benabdelkamel, H.; Perri, E.; Russo, A.; Sindona, G. Effects of conventional heating on the stability of major olive oil phenolic compounds by tandem mass spectrometry and isotope dilution assay. Molecules 2010, 15, 8734-8746. [CrossRef] [PubMed]

68. Zafra-Gómez, A.; Luzón-Toro, B.; Capel-Cuevas, S.; Morales, J.C. Stability of Hydroxytyrosol in Aqueous Solutions at Different Concentration, Temperature and with Different Ionic Content: A Study Using UPLC-MS. Food Nutr. Sci. 2011, 02, 1114-1120. [CrossRef]

69. Tu, J.L.; Yuan, J.J. Thermal decomposition behavior of hydroxytyrosol (HT) in nitrogen atmosphere based on TG-FTIR methods. Molecules 2018, 23, 404. [CrossRef]

70. Vogna, D.; Pezzella, A.; Panzella, L.; Napolitano, A.; D'Ischia, M. Oxidative chemistry of hydroxytyrosol: Isolation and characterisation of novel methanooxocinobenzodioxinone derivatives. Tetrahedron Lett. 2003, 44, 8289-8292. [CrossRef]

71. De Lucia, M.; Panzella, L.; Pezzella, A.; Napolitano, A.; D'Ischia, M. Oxidative chemistry of the natural antioxidant hydroxytyrosol: Hydrogen peroxide-dependent hydroxylation and hydroxyquinone/o-quinone coupling pathways. Tetrahedron 2006, 62, 1273-1278. [CrossRef]

72. Araki-Sasaki, K.; Ohashi, Y.; Sasabe, T.; Hayashi, K.; Watanabe, H.; Tano, Y.; Handa, H. An SV40-immortalized human corneal epithelial cell line and its characterization. Investig. Ophthalmol. Vis. Sci. 1995, 36, 614-621.

73. Di Mauro, M.D.; Ferrito, V.; Scifo, C.; Renis, M.; Tomasello, B. Effectiveness of Natural Compounds on DNA Damage in Coris julis (Linneaus 1758) from a Polluted Marine Area. Water Air Soil Pollut. 2017, 228, 228. [CrossRef]

74. Greenspan, L. Humidity Fixed Points of Binary Saturated Aqueous Solutions. J. Res. Natl. Bur. Stand. 1977, 81, 89-96. [CrossRef] 